\title{
Experimental investigation of the in-plane cyclic behaviour of calcium silicate brick masonry walls
}

\author{
F. Messali ${ }^{1}$ (D) R. Esposito ${ }^{1}$ (D) . G. J. P. Ravenshorst ${ }^{2}$. J. G. Rots ${ }^{1}$
}

Received: 17 April 2019 / Accepted: 24 March 2020 / Published online: 5 April 2020

(C) The Author(s) 2020

\begin{abstract}
The material and structural performance of calcium silicate (CS) brick masonry has received relatively little attention in the past, although this material is often used for the construction of low-rise buildings in Central and Northern Europe. Upon the occurrence of induced seismicity in the north of the Netherlands, an extensive testing programme has been conducted since 2014 at Delft University of Technology. The paper presents the outcomes of eight quasi-static cyclic tests performed within this program on CS brick masonry walls under vertical and lateral in-plane loads. Different dimensions, boundary conditions and applied pre-compression loads were considered. Overall, the tests allowed to characterise the in-plane behaviour of CS brick masonry walls. The results confirmed the influence of the shear ratio (i.e. the ratio between the effective height and the length of the wall) on the wall response in terms of prevailing failure mode, initial stiffness, force and deformation capacity, energy dissipation. Besides, the experimental outcomes stressed the difficulty in estimating the effective stiffness and near collapse drift capacity. Additionally, an empirical equation is proposed to predict the peak lateral force. The equation, calibrated against the tests presented in this paper, was validated against an extended dataset of tests performed on CS masonry walls. The equation, which does not need any input of material parameters and is applicable irrespectively of the expected failure mode, can be used to estimate the force capacity of CS masonry walls when no or limited data on the material properties are available.
\end{abstract}

Keywords Unreinforced masonry (URM) · Calcium silicate (CS) bricks $\cdot$ In-plane response $\cdot$ Quasi-static cyclic tests · Displacement and force capacity $\cdot$ Hysteretic behaviour

\section{List of symbols}

$d \quad$ Net top horizontal displacement of the tested walls

$d_{E}, d_{W} \quad$ Vertical distance between top and bottom steel beam in the set-up on east and west side, respectively

$f_{b} \quad$ Normalized compressive strength of masonry units

$f_{b t} \quad$ Flexural strength of masonry units

F. Messali

f.messali@tudelft.nl

Extended author information available on the last page of the article 
$f_{c} \quad$ Compressive strength of masonry measured perpendicular to bed-joints

$f_{c h} \quad$ Compressive strength of masonry measured parallel to bed-joints

$f_{m} \quad$ Compressive strength of mortar

$f_{m t} \quad$ Flexural strength of mortar

$f_{v 0} \quad$ Initial shear strength of masonry

$f_{v d} \quad$ Design shear strength of masonry

$f_{v p} \quad$ Mean shear strength of masonry at peak

$f_{v u} \quad$ Ultimate shear strength of masonry

$f_{w} \quad$ Flexural bond strength of masonry

$h_{\text {ref }} \quad$ Reference height of the wall (equal to $2.4 \mathrm{~m}$ )

$h_{w} \quad$ Height of the wall

$h_{w 0} \quad$ Effective height of the wall

$k_{\text {eff }} \quad$ Effective stiffness of the wall

$k_{e l} \quad$ Elastic stiffness of the wall

$k_{\text {in }} \quad$ Initial stiffness of the wall

$l_{v a} \quad$ Horizontal distance between the east and west pairs of vertical actuators

$l_{w} \quad$ Length of the wall

$l_{\mathrm{w}}^{\prime} \quad$ Length of the uncracked section at the base of the wall

$\tan \varphi \quad$ Shear friction coefficient of masonry

$t_{w} \quad$ Thickness of the wall

$A, B \quad$ Dimensionless calibrated constant values

$A_{w} \quad$ Area of the wall section

CV Coefficient of variation

$E_{1} \quad$ Secant elastic modulus of masonry subject to a compressive loading perpendicular to the bed joints, evaluated at $1 / 3$ of the maximum stress

$E_{1 h} \quad$ Secant elastic modulus of masonry subject to a compressive loading parallel to the bed joints, evaluated at $1 / 3$ of the maximum stress

$E_{2} \quad$ Secant elastic modulus of masonry subject to a compressive loading perpendicular to the bed joints, evaluated at $1 / 10$ of the maximum stress

$E_{2 h} \quad$ Secant elastic modulus of masonry subject to a compressive loading parallel to the bed joints, evaluated at $1 / 10$ of the maximum stress

$E_{3} \quad$ Secant elastic modulus of masonry subject to a compressive loading perpendicular to the bed joints, evaluated between $1 / 10$ and $1 / 3$ of the maximum stress

$E_{3 h} \quad$ Secant elastic modulus of masonry subject to a compressive loading parallel to the bed joints, evaluated between $1 / 10$ and $1 / 3$ of the maximum stress

$G \quad$ Shear modulus of masonry

$H \quad$ Vertical distance between the point of application of the horizontal force and the wall base

$I_{w} \quad$ Moment of inertia of the wall section

$M_{L} \quad$ Local magnitude of an earthquake

$N \quad$ Total compressive load applied on top of the wall

$V_{c r} \quad$ Shear force at onset of cracking

$V_{E}, V_{W} \quad$ Measured forces in each pair of vertical actuators in the test set-up on east and west side, respectively

$V_{f} \quad$ Base shear force capacity predicted by standards for flexural failure

$V_{H} \quad$ Base shear force

$V_{p} \quad$ Peak base shear force capacity

$V_{p, p r e d} \quad$ Predicted peak shear force capacity 


$\begin{array}{ll}V_{s} & \text { Base shear force capacity predicted by standards for shear failure } \\ V_{u} & \text { Ultimate shear force } \\ \mathrm{W}_{\mathrm{el}}^{+}, \mathrm{W}_{\mathrm{el}}^{-} & \text {Elastic energy for positive and negative displacements for each cycle } \\ W_{i} & \text { Dissipated energy for each test cycle } \\ \alpha & \text { Dimensionless coefficient that describes the wall boundary conditions } \\ \delta & \text { Drift of the wall } \\ \delta_{c r} & \text { Drift at onset of cracking } \\ \delta_{e l} & \text { Elastic drift } \\ \delta_{\text {max }}, \delta_{\text {min }} & \text { Maximum and minimum drift, respectively } \\ \delta_{p} & \text { Drift at peak force } \\ \delta_{u} & \text { Ultimate drift } \\ \delta_{u, p r e d} & \text { Predicted ultimate drift } \\ \kappa & \text { Timoshenko shear coefficient } \\ \xi_{\text {hyst }} & \text { Equivalent hysteretic damping coefficient } \\ \rho & \text { Density of masonry } \\ \sigma_{v} & \text { Average vertical stress } \\ \mu & \text { Friction coefficient } \\ \mu_{c y c l e} & \text { Ductility of the wall computed as the ratio between the drift of the wall } \delta \text { at the } \\ \mu_{u} & \text { end of each cycle and the elastic drift } \delta_{e l}\end{array}$

\section{Introduction}

Unreinforced masonry (URM) is an accessible, sustainable and popular building material. At the same time, the performance of URM buildings in seismic regions must be carefully assessed, since these proved to be vulnerable to earthquakes in several events occurred around the world (e.g. Bruneau 2002; Ceci et al. 2010; Penna et al. 2014; Potter et al. 2015). Among the different masonry typologies, the performance at material and structural scale of calcium silicate (CS) brick masonry received relatively little attention in the past. In fact, this type of masonry has been traditionally used in buildings with cavity wall systems, especially in terraced and detached houses built between 1960 and 1980, and such buildings can be mainly found in central and northern European countries that are characterised by low natural seismicity. Since 1980s, the CS bricks have been then gradually replaced by larger units (CS blocks or elements) in combination with thin layer mortar joints. A first experimental investigation was performed on CS masonry within the European project Enhanced Safety and Efficient Construction of Masonry Structures in Europe (ESECMASE) in the years 2004-2008, which aimed, inter alia, to improve the understanding of the behaviour of shear loaded masonry in typical masonry structures. During this campaign, large quasi-static cyclic tests were performed at the laboratories of the University of Pavia (Magenes et al. 2008), Kassel University (Fehling et al. 2008), and Technical University of Munich (Zilch et al. 2008). However, the investigation considered CS block masonry, rather than CS brick masonry. CS block masonry was also studied by Ötes and Löring (2003), Mojsilovic (2011), and Salmanpour et al. (2015), and CS element masonry by van der Meer et al. (2013), and Jafari et al. (2018).

A boost to investigate the CS brick masonry performance was given by the occurrence of induced seismicity in the province of Groningen (north of the Netherlands), where the exploitation of gas has been triggering shallow earthquakes. Even though these seismic 
events have been characterised by small magnitudes (a maximum local magnitude $M_{L}=3.6$ was recorded in 2012 in Huizinge), probabilistic investigations showed that larger magnitudes may be expected (Vlek 2018). Besides, CS masonry terraced and detached houses have specific characteristics that can limit their seismic performance, and the investigation of their structural behaviour under lateral loads has become a matter of high relevance. In this framework, a comprehensive experimental campaign has been carried out since 2014 in a few European laboratories, including the Macrolab/Stevinlaboratory at Delft University of Technology (TU Delft), with a large part of this research focusing on CS brick masonry (Messali et al. 2018; Graziotti et al. 2018). The dynamic behaviour was studied at the laboratories of Eucentre in Italy and LNEC in Portugal, with experimental tests on single leaf and cavity walls under in-plane (Graziotti et al. 2016a) and out-ofplane (Graziotti et al. 2016b, 2019) loading, as well as on full-scale structures (Graziotti et al. 2017; Tomassetti et al. 2019). The investigation at TU Delft considered quasi-static cyclic loading and was characterised by a multiscale approach, with tests at material (Jafari et al. 2017, 2018), connection (Skroumpelou et al. 2018), component (Messali et al. 2017; Damiola et al. 2018), and structural (Esposito et al. 2017, 2019) level.

In the present work, the experimental outcomes of eight quasi-static cyclic tests at component level on full-scale CS brick masonry walls tested under in-plane loading are presented. The results are reported in terms of hysteretic behaviour and equivalent bilinear curves, and the influence of the wall characteristics, such as geometry, boundary conditions, and pre-compression is discussed.

\section{Materials and methods}

\subsection{Description of specimens and materials}

Eight full-scale URM walls were built and tested at Delft University of Technology to study the in-plane behaviour of CS brick masonry walls. Two series of solid CS brick masonry walls having different geometry were considered. Specimens TUD-COMP-0a, TUD-COMP-1, TUD-COMP-2, TUD-COMP-3, and TUD-COMP-20 were characterised by high aspect ratio, and will be hereinafter referred to as "slender walls", whereas specimens TUD-COMP-4, TUD-COMP-5, and TUD-COMP-6 had a low aspect ratio, and will be referred to as "squat walls". It should be noted that the abbreviation COMP refers to the term "component", and not to "compression" as in other works in the literature. The tests presented different boundary conditions at wall ends: four cantilever walls, and three double clamped walls. Finally, the walls were subjected to different levels of vertical precompression stress.

Table 1 provides an overview of the properties of the tested specimens, where $l_{w}, h_{w}$, and $t_{w}$ are the length, the height, and the thickness of the walls, respectively, and $\sigma_{v}$ is the vertical pre-compression stress applied at the top of the walls. The aspect ratio is computed as the ratio between height $h_{w}$ and length $l_{w}$ of the wall, and the shear ratio as the ratio between the effective height of the wall $h_{w 0}$ and the length $l_{w}$ of the wall. The effective height $h_{w 0}$ corresponds to the distance between the zero moment section and the base.

The tested specimens were made of masonry composed of solid CS bricks and general purpose mortar, selected on the basis of the outcomes of a previous experimental campaign, in which masonry samples had been extracted from existing buildings and tested in the laboratory (Jafari et al. 2017). The CS bricks had nominal dimensions of $210 \times 71 \times 102 \mathrm{~mm}$. 
Table 1 Summary of the specimen properties

\begin{tabular}{|c|c|c|c|c|c|c|}
\hline \multirow[t]{2}{*}{ Specimen name } & \multirow[t]{2}{*}{$\begin{array}{l}\text { Testing } \\
\text { year }\end{array}$} & \multirow{2}{*}{$\begin{array}{l}\text { Dimensions } \\
l_{w} \times h_{w} \times t_{w}(\mathrm{~m})\end{array}$} & $\begin{array}{l}\text { Aspect } \\
\text { ratio }\end{array}$ & \multirow[t]{2}{*}{$\begin{array}{l}\text { Boundary } \\
\text { conditions }\end{array}$} & \multirow{2}{*}{$\begin{array}{l}\text { Shear ratio } \\
h_{w 0} / l_{w}(-)\end{array}$} & \multirow{2}{*}{$\begin{array}{l}\text { Vertical pre- } \\
\text { compression } \\
\sigma_{v}(\mathrm{MPa})\end{array}$} \\
\hline & & & $h_{w} / l_{w}(-)$ & & & \\
\hline TUD-COMP-0a & 2015 & $1.1 \times 2.76 \times 0.102$ & 2.5 & $\begin{array}{l}\text { Double } \\
\text { clamped }\end{array}$ & 1.25 & 0.70 \\
\hline TUD-COMP-1 & 2015 & $1.1 \times 2.76 \times 0.102$ & 2.5 & Cantilever & 2.90 & 0.70 \\
\hline TUD-COMP-2 & 2015 & $1.1 \times 2.76 \times 0.102$ & 2.5 & Cantilever & 2.90 & 0.50 \\
\hline TUD-COMP-3 & 2015 & $1.1 \times 2.76 \times 0.102$ & 2.5 & $\begin{array}{l}\text { Double } \\
\text { clamped }\end{array}$ & 1.25 & 0.40 \\
\hline TUD-COMP-4 & 2015 & $4.0 \times 2.76 \times 0.102$ & 0.7 & $\begin{array}{l}\text { Double } \\
\text { clamped }\end{array}$ & 0.35 & 0.50 \\
\hline TUD-COMP-5 & 2015 & $4.0 \times 2.76 \times 0.102$ & 0.7 & $\begin{array}{l}\text { Double } \\
\text { clamped }\end{array}$ & 0.35 & 0.30 \\
\hline TUD-COMP-6 & 2015 & $4.0 \times 2.76 \times 0.102$ & 0.7 & Cantilever & 0.80 & 0.50 \\
\hline TUD-COMP-20 & 2016 & $1.1 \times 2.76 \times 0.102$ & 2.5 & Cantilever & 2.78 & 0.63 \\
\hline
\end{tabular}

The general purpose cement-based mortar was prepared with fixed water content: 2.81 every $25 \mathrm{~kg}$ of product. A running bond was used for every wall and both bed- and headjoints were $10 \pm 1 \mathrm{~mm}$ thick, and fully filled. The walls were masoned and tested in two different periods: specimens TUD-COMP-0a to TUD-COMP-6 were built and tested in 2015, while TUD-COMP-20 in 2016. All used materials belonged to the same production batch. Every wall was stored in the laboratory for at least 28 days before testing. Similar to the full-scale walls, also the companion material tests were performed in two time periods. Overall, similar properties were measured with the exception of the Young's modulus and of the flexural bond strength of masonry. Table 2 lists the material properties obtained from both the testing periods, along with the followed reference standard.

\subsection{Test set-up and procedure}

Figure 1 shows a scheme of the test set-up. The frame was designed in order to provide both a uniform vertical pressure (throughout four actuators, having each a capacity of 100 $\mathrm{kN}$ ) and an imposed horizontal displacement (via an actuator with a capacity of $400 \mathrm{kN}$ ) at the top of the walls. The top and bottom brick course of each specimen was glued to a steel beam with a high performance glue to prevent sliding or tensile failure at the steelmasonry interface. It should be noted that this solution slightly modifies the location where the damage can start with respect to a URM wall on concrete foundations, since no damage can occur along the interfaces with the steel beams. The bottom steel beam was rigidly connected to other cross-beams anchored to the strong concrete laboratory floor, whereas a load-spreading beam was bolted over the top steel beam and connected to the horizontal actuator. The height of application of the load with respect to the wall base is identified by $H$ in Fig. 1. The offset between the height of application of the load and the height of the wall caused small bending moment at the top of the cantilever walls, so that the moment profile of these specimens did not strictly correspond to that of a cantilever wall. For this reason the shear ratio of these walls differs from the aspect ratio. In the test set-up used for the tests carried out in 2015 , the actuator was connected at the west end of the steel 


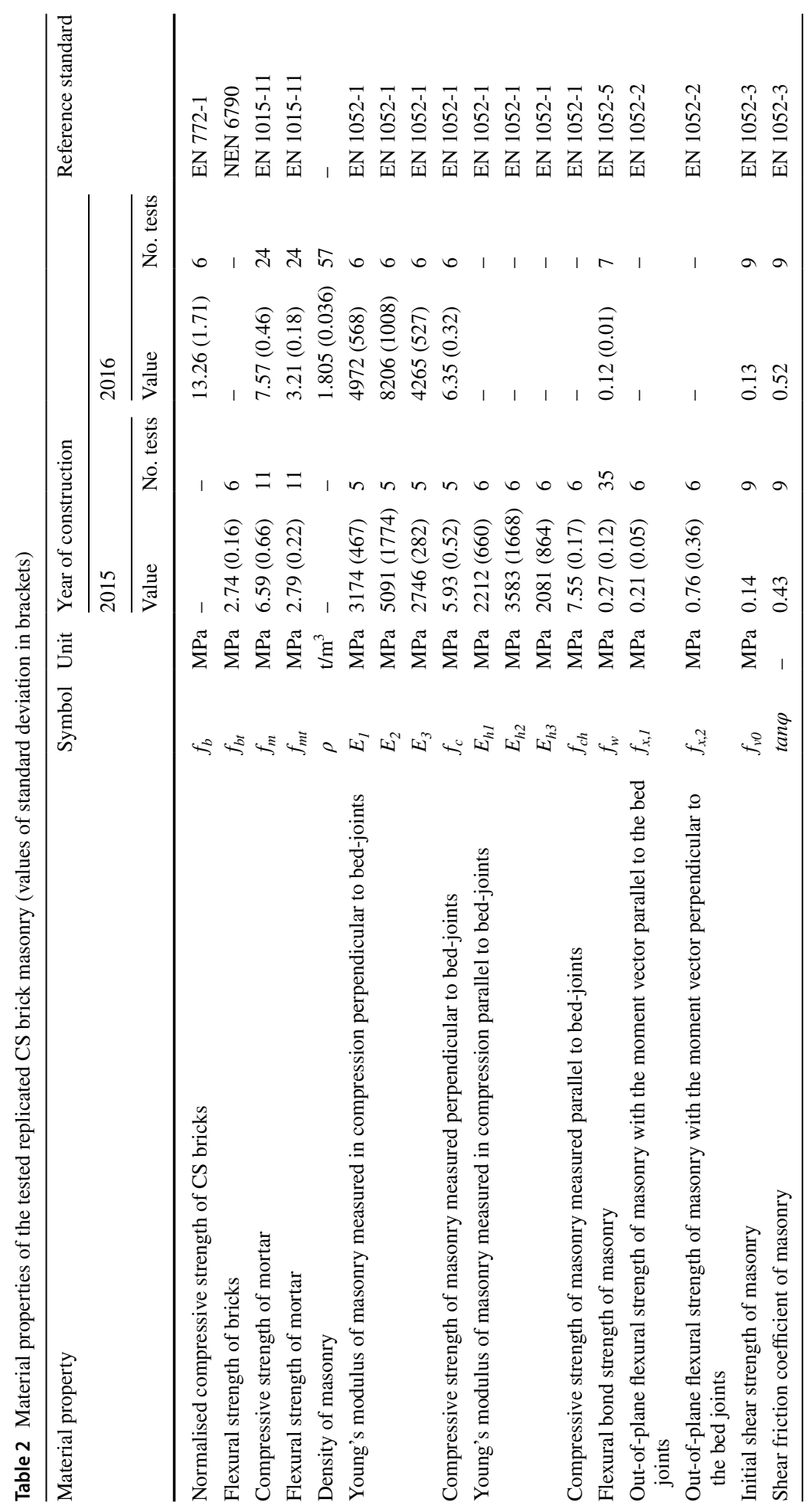




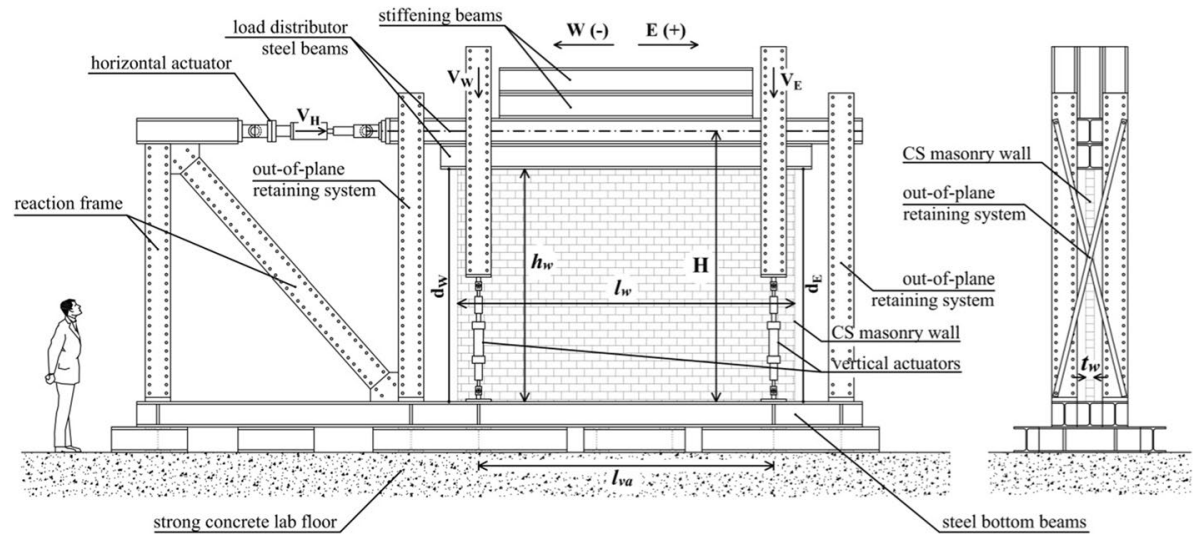

Fig. 1 Test set-up

beam. This detail was modified in 2016, when the actuator was connected directly to the centre of the steel beam by means of two steel tubes, one at each side of the beam (Esposito and Ravenshorst 2017) (the detail is not shown in Fig. 1). The weight of the actuator was always balanced by a counter weight in both the testing periods. The vertical actuators connected the cross-beams at the base of the wall to the load-spreading beam on the top. The four actuators were controlled pairwise (on the front and back of the wall) to ensure that the load in each actuator of the pair was the same. The distance $l_{v a}$ between each pair of actuators was equal to $1.9 \mathrm{~m}$ for the slender walls, and $3.7 \mathrm{~m}$ for the squat walls. Given the large distance between the two couples of vertical actuators in the configuration used for the tests on squat walls, two additional steel beams were added above the load-spreading beam to ensure a uniform spreading of the vertical load. The out-of-plane displacements and rotations of the top beam were prevented by a transversal steel frame (in Fig. 1 only the columns are shown).

Every tested wall was instrumented with a series of linear potentiometers and draw wires to measure the displacements of specific portions of the specimen. Specifically, the following quantities were measured: force and displacements in the horizontal and vertical actuators; horizontal displacements at top and bottom of the specimen; vertical and diagonal displacements at the specimen corners; sliding between the extreme rows of bricks and the steel beams; deformations at the four corners. Additionally, three lasers measured the out-of-plane displacements at the base, in the middle, and at the top of the walls, respectively.

Each wall was tested in displacement control under quasi-static conditions. The specimen was initially subjected to the targeted level of vertical pre-compression, which remained constant throughout the whole duration of the test. Then horizontal displacements were applied to the top of the specimen through the software-controlled actuator, with cycles of increasing amplitude. An initial cycle in load control was performed up to $20 \%$ of the expected peak lateral force and the corresponding displacement was measured. The amplitude of the following cycles was then determined as multiple of this displacement. Each cycle was composed of three runs, being a run defined as the time needed to apply the maximum positive and negative target displacement starting and ending at zero displacement. An increasing speed rate was adopted so that every cycle lasted about $10 \mathrm{~min}$ until a maximum rate of $1.5 \mathrm{~mm} / \mathrm{sec}$ was achieved, then that rate was maintained. The tests 
were stopped based on visual inspections when the integrity of the wall was considered jeopardized and the continuation of the test might lead to the collapse of the specimen, or due to limitations of the set-up that did not allow to proceed further, as described in the next section. The complete loading sequence for each test performed is reported in Table 3 in terms of net horizontal displacement, computed as the difference between the displacements measured at the top and at the bottom of the wall, respectively.

As mentioned above, the testing programme considered two different boundary conditions: cantilever and double clamped boundary conditions. For the cantilever case the load was maintained constant in each vertical actuator: $V_{E}=V_{W}$, where $V_{E}$ and $V_{W}$ were the measured forces in each pair of actuators (as shown in Fig. 1). For the double clamped walls the forces in the actuators were dynamically updated according to a mixed force-displacement control of the vertical actuators, by means of which the total vertical load was maintained constant $\left(V_{E}+V_{W}=\right.$ const.) and the top beam horizontal $\left(d_{E}=d_{W}\right.$, see Fig. 1$)$. For the double-clamped tests the height of the inflection point (i.e. the point of zero moment) is conventionally taken as half of the height of the wall. Although this is not valid throughout the whole duration of the test, it can be observed that the values of the height of the inflection point measured at the peak displacements of each cycle are indeed distributed around the half of the height of the wall, as shown in Fig. 2 for a slender and a squat wall.

The mixed force-displacement control of the vertical actuators was recommended in works where similar in-plane tests on single URM walls were also performed, because it allows a better control of the test when the walls are severely damaged (Magenes et al. 2008; Salmanpour et al. 2015). However, even this control procedure may be unstable, as occurred during the test of wall TUD-COMP-5. In fact, the displacements $d_{E}$ and $d_{W}$ (Fig. 1), used to maintain the horizontality of the top beam, are read by two linear potentiometers next to the wall. Generally, these readings coincide approximately with those measured by the LVDTs integrated in the vertical actuators, but the analysis of the data of the test on wall TUD-COMP-5 showed that the readings in the couple of actuators on the west side deviated from those of the corresponding potentiometers when critical compressive displacements were reached (Fig. 3). This deviation altered the forces in the actuators, so that larger negative compressive forces (that could generate the instability of the loading system) where gradually required in the actuators of the west side to maintain horizontal the top steel beam. During the test it was then decided to continue the loading procedure only in the negative loading direction in order to maintain positive tensile forces (or small compressive forces) in the actuators. To avoid such problems, it is advised to limit the deformation in compression of the vertical actuators. Alternatively, the control of the beam horizontality can be achieved via a precise inclinometer attached to the steel beam.

\section{Experimental results}

The performed tests allowed to evaluate the behaviour of the specimens under cyclic loading in terms of force-displacement curves, crack development, identification of the load at the onset of cracking and at peak, predominant failure mode, and deformation capacity. Table 4 summarises the most relevant results of the experimental tests. $V_{c r}$ and $V_{p}$ are the loads at the onset of cracking and at peak, respectively, and $\delta_{c r}$ and $\delta_{p}$ the corresponding drifts, being the drift $\delta$ computed as the ratio between the wall net displacement and the wall height $\left(d / h_{w}\right) . \delta_{\max }$ and $\delta_{\min }$ are the maximum and minimum drift, respectively, 


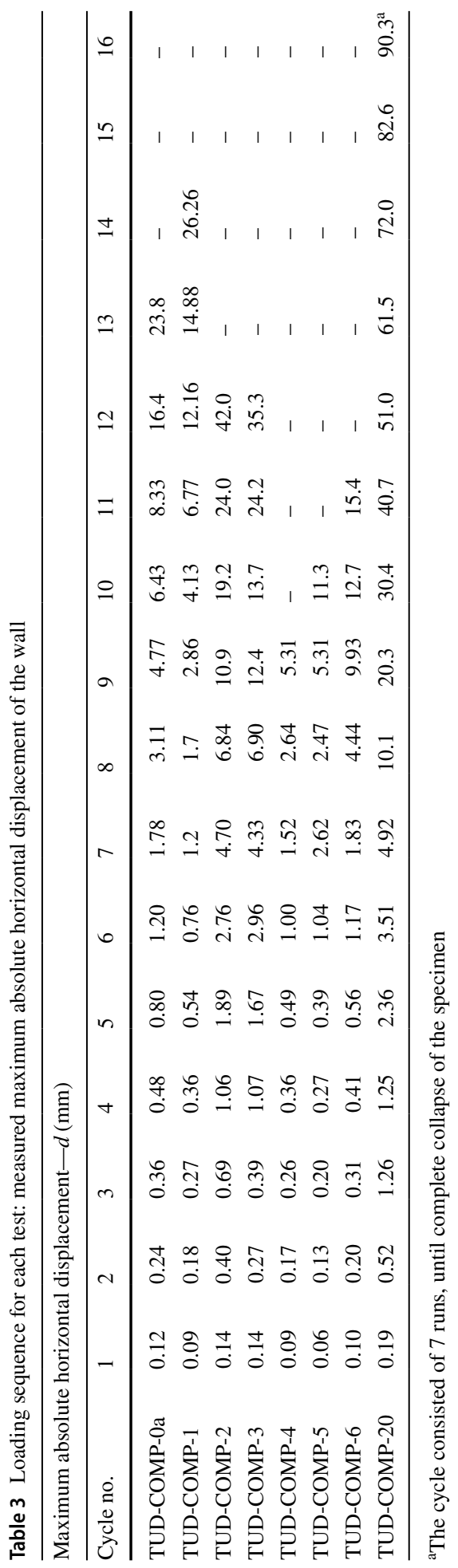



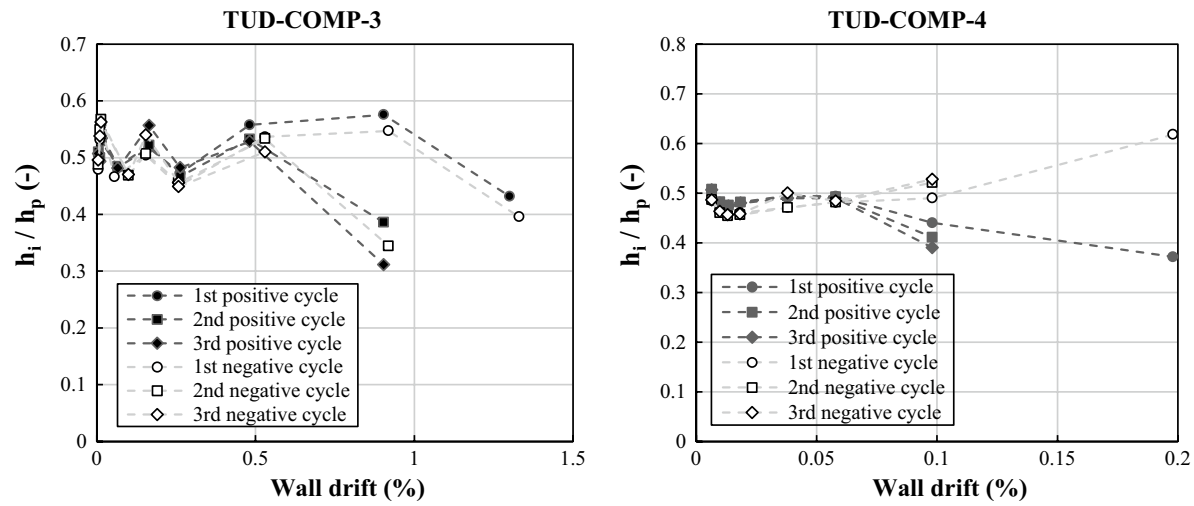

Fig. 2 Height of the inflection point at the peak displacements normalized with respect to the wall height, for a slender wall (TUD-COMP-3) and a squat wall (TUD-COMP-4)

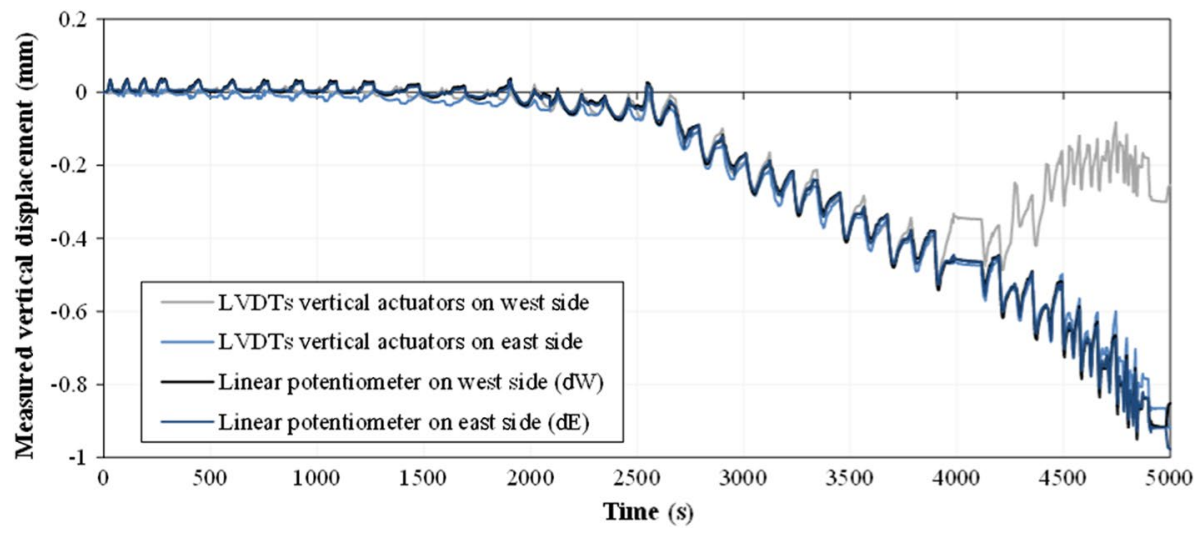

Fig. 3 Vertical displacements measured by the LVDTs in the vertical actuators and by the linear potentiometers on the side of the wall

achieved during the test. The values are provided for both positive and negative imposed displacements.

\subsection{Hysteretic response of the tested specimens}

The hysteretic behaviour of the tested walls is discussed in this section for the slender and the squat walls. The complete hysteretic response, the backbone curve (computed as the envelope of the cyclic curve), and the equivalent bilinear curve of the walls are presented in Fig. 4, while Fig. 5 shows the first visible crack and the crack pattern as detected at the end of the tests.

The behaviour of the slender walls was overall characterised by rocking behaviour (Fig. 6a), with first cracks opening along the bed-joints at corners (only at the bottom for cantilever walls, as shown in Fig. 7a). In the following cycles new flexural cracks originated at higher level and short diagonal cracks opened close to the corners (Fig. 7b). After 


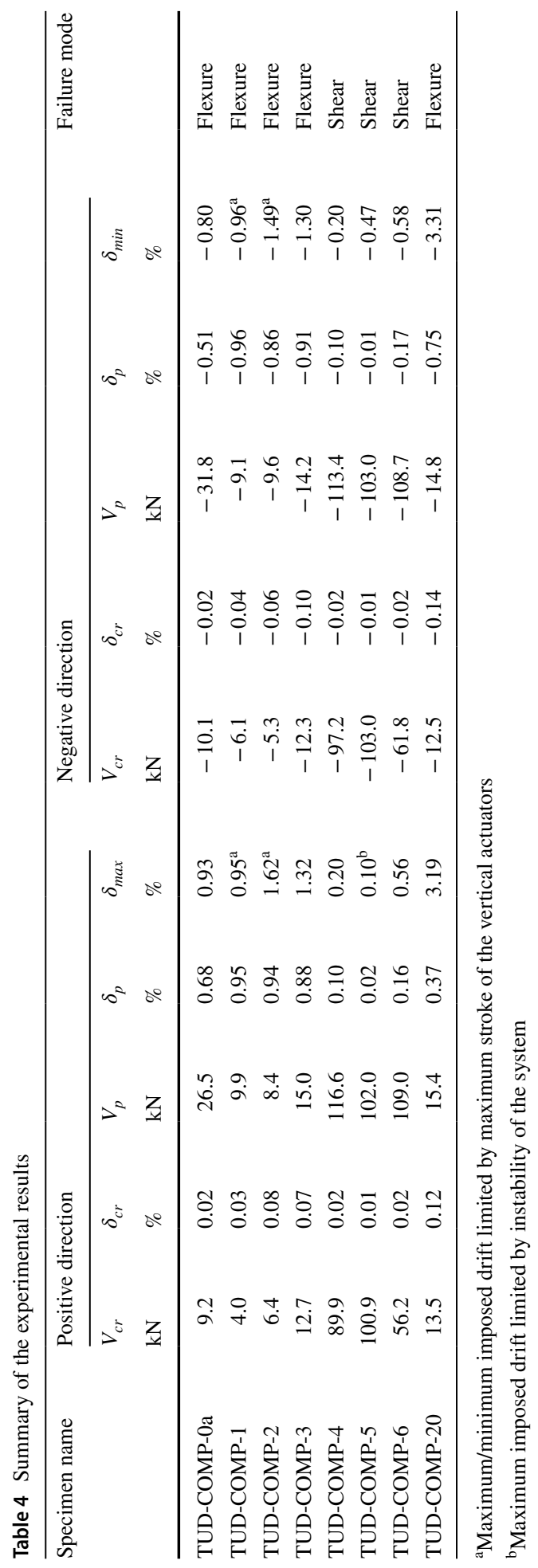



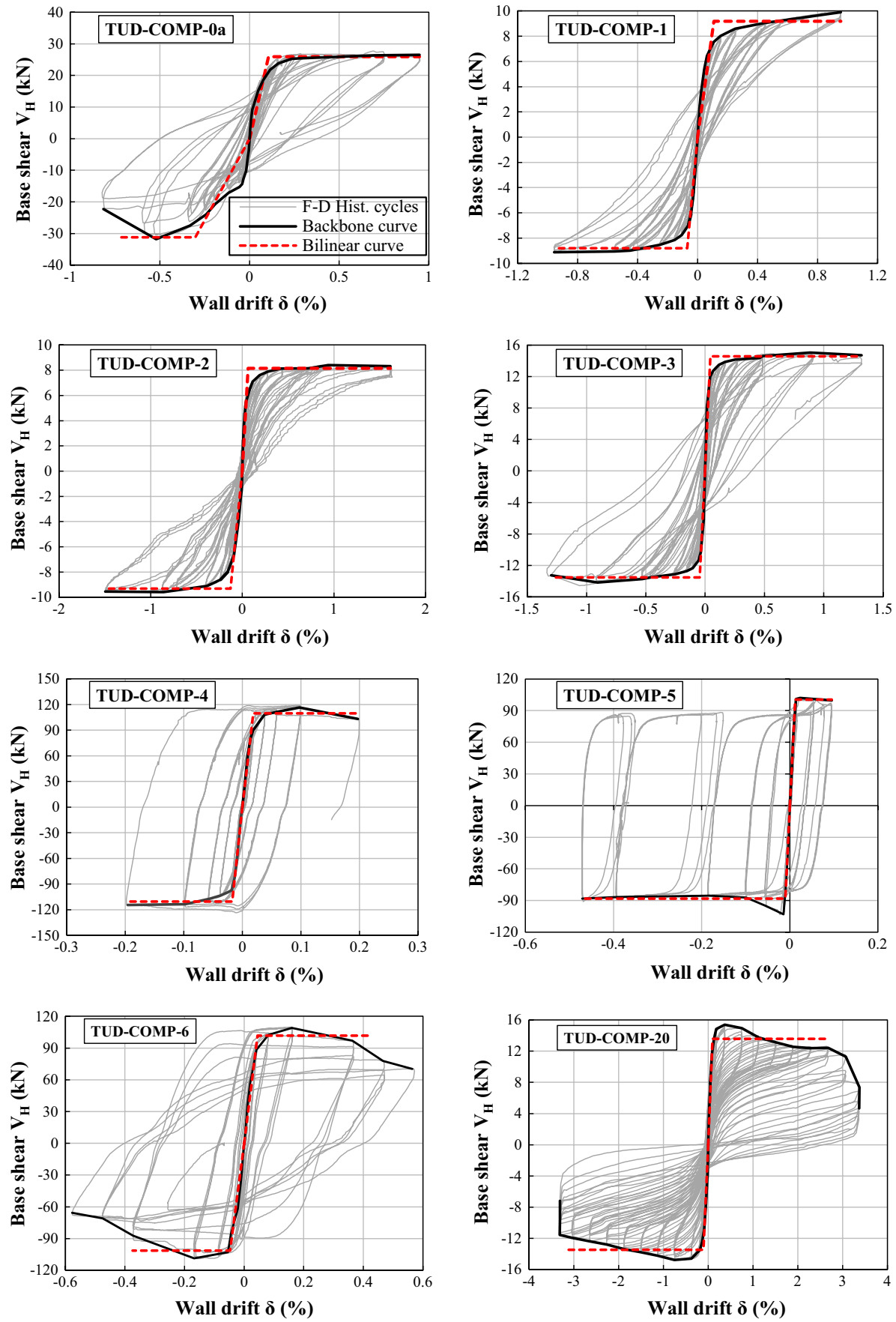

Fig. 4 Hysteretic curves, backbone curves (thicker black lines), and equivalent bilinear curves (red dashed lines) for the eight performed experiments 


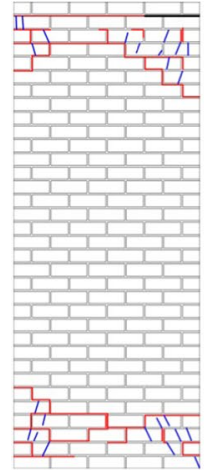

TUD-COMP-0a

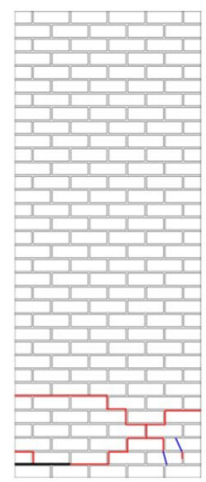

TUD-COMP-2

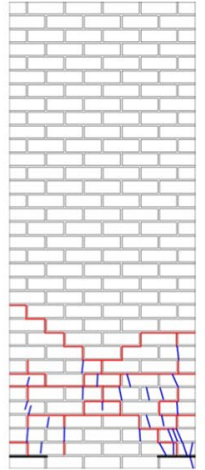

TUD-COMP-1

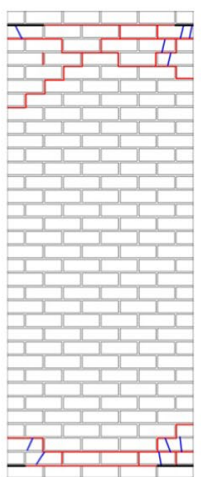

TUD-COMP-3

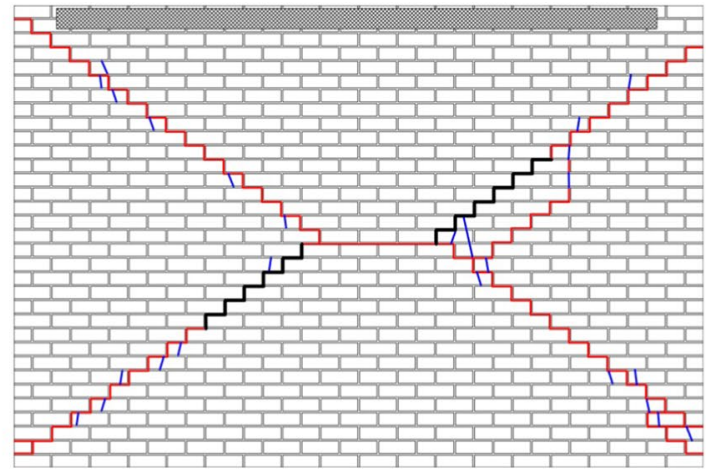

TUD-COMP-4

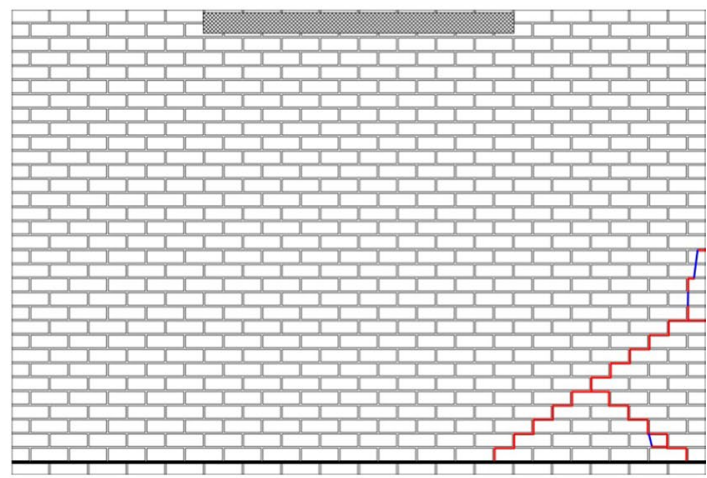

TUD-COMP-5

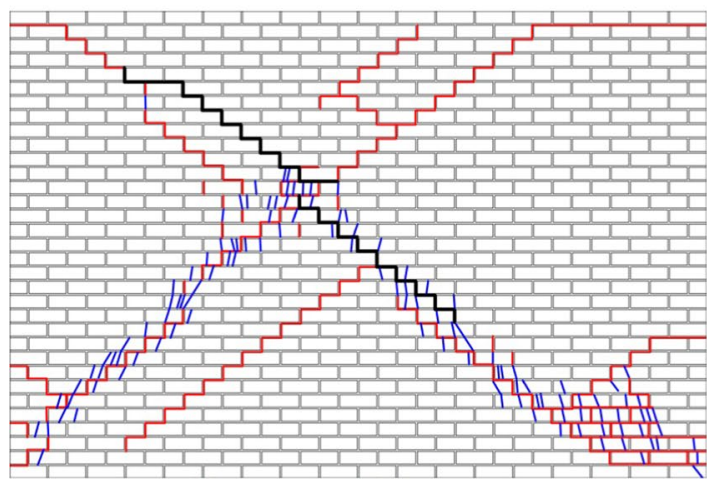

TUD-COMP-6

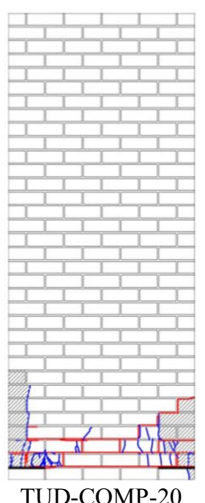

Legend:

cracks along mortar joints cracks through bricks

- first crack masonry collapsed during cycles $12 / 13$ glued steel patch

Fig. 5 Crack pattern detected at the end of the tests

that the lateral force capacity was achieved, the rocking mechanism continued together with some sliding along the cracks (with the exception of specimen TUD-COMP-2), as shown in Fig. 7c. Splitting cracks in the bricks and compressive toe crushing occurred at large drifts, determining a progressive loss of strength, and leading eventually to the complete collapse of specimen TUD-COMP-20. The tests performed on walls TUD-COMP-1 and TUD-COMP-2 were stopped due to limitations of the set-up after the maximum stroke of 

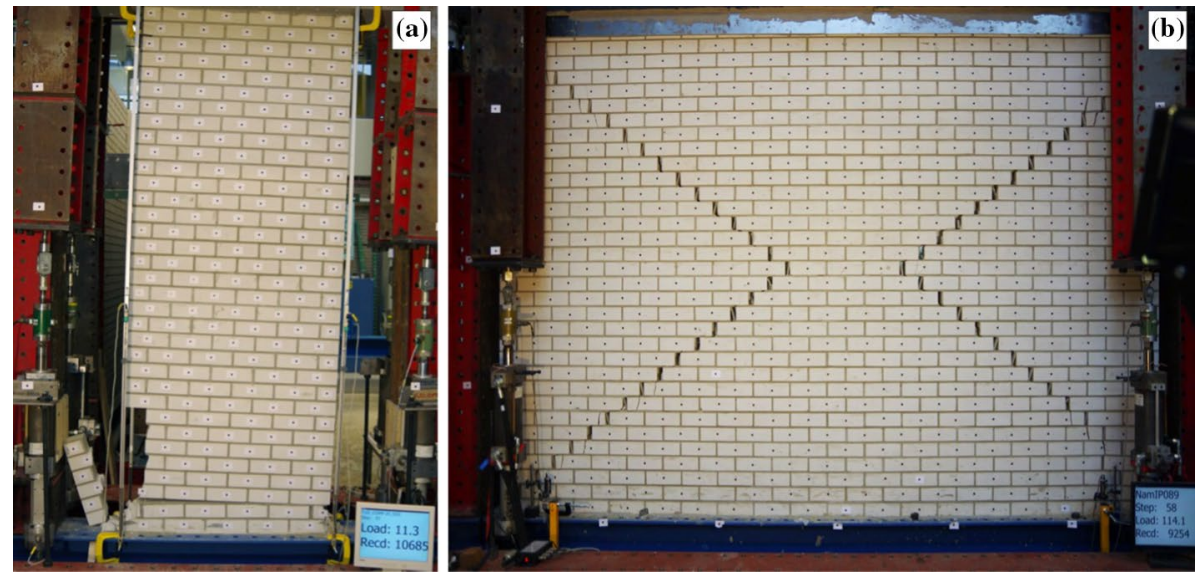

Fig. 6 Crack pattern of the specimens at maximum positive drift for slender walls (TUD-COMP-20) (a) and squat walls (TUD-COMP-4) (b)
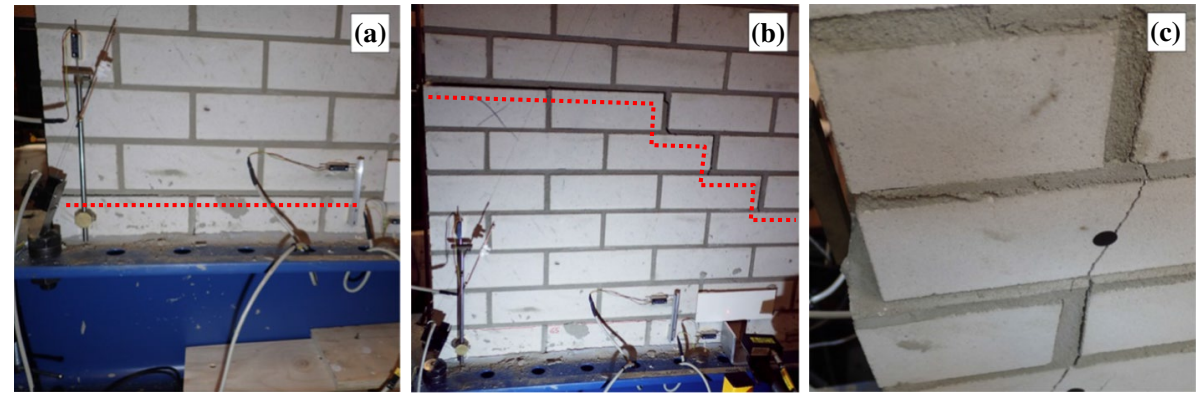

Fig. 7 Details of the observed crack pattern for specimen TUD-COMP-1: initial crack at the base of the slender walls (a), and crack migrated in the following cycles (b); residual sliding at the end of the test (c)

the vertical actuators was reached. In the subsequent tests the initial position of the actuators was modified, so that this issue did not occur again. Besides, the measured peak force of specimen TUD-COMP-1 was considerably lower than the values returned by analytical and numerical simulations.

The three squat walls were all characterised by shear dominated failure (Fig. 6b). Shear sliding occurred along the mortar bed-joints, with progressive widening of residual cracks perpendicular to the head-joints (a maximum residual crack width of about $50 \mathrm{~mm}$ was observed at the end of the tests). The shear cracks outlined distinct portions of the walls (Figs. 5 and 6b), with those near the sides gradually pushed out the wall. The tests were stopped when these portions were about to be pushed out completely (Fig. 8a). In detail, each wall's behaviour was slightly different from the others. Diagonal shear cracks opened close to the centre of walls TUD-COMP-4 and TUDCOMP-6 and then quickly expanded to the corners, whereas the failure of specimen TUD-COMP-5 was mainly characterised by sliding along the mortar joint on top of the first layer of bricks. Also the appearance of the diagonal cracks in specimens TUDCOMP-4 and TUD-COMP-6 was different: while in the former a clear main crack could 

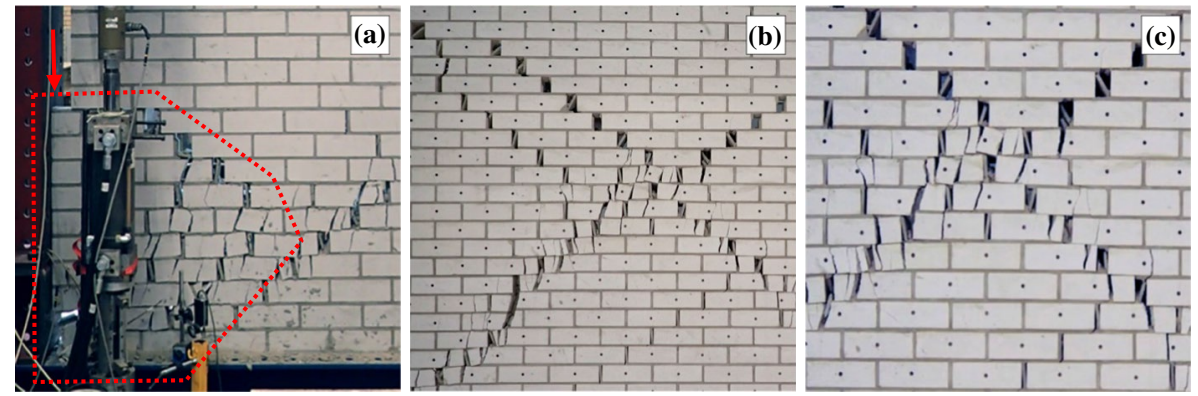

Fig. 8 Details of the observed crack pattern for specimen TUD-COMP-6: left toe close to be pushed out the wall at the end of the test (a); multiple diagonal cracks (b); cracks passing through the bricks in the middle of the panel (c)

be observed, several parallel cracks opened along the main diagonals of the latter in subsequent cycles (Fig. 8b). Moreover, for TUD-COMP-6 significant cracking of the bricks was observed, especially in the middle of the panel, where the two compressed struts crossed each other (Fig. 8c), and at toes. It should be also noted that a horizontal crack formed along the first top mortar layer of walls TUD-COMP-4 and TUD-COMP-5 while connecting the steel beam glued on top of the wall to the load distributor beam and the stiffening beams, because these were slightly deflected. This problem was solved with wall TUD-COMP- 6 by changing the order in which the bolts were tightened. The crack was repaired by gluing steel plates on both sides of the wall (as shown in Figs. 5 and $6 \mathrm{~b}$ ), so that a stiff connection between the first and second top bricklayers was created. That prevented the crack to develop along that joint, but did not change the overall behaviour of the wall. Nevertheless, this procedure is not recommended, and replacement of the top masonry course could have been a suitable alternative.

\subsection{Equivalent bilinear curves}

The cyclic response of in-plane experimental tests is commonly idealised by bilinear curves. Each curve requires the definition of three parameters: the effective stiffness $k_{\text {eff }}$, the ultimate shear force $V_{u}$, and the ultimate drift capacity $\delta_{u}$. The value of these parameters was computed in this study following the approach proposed in past works (e.g. Salmanpour et al. 2015; Morandi et al. 2018). The effective stiffness, i.e. the elastic stiffness of the bilinear curve, is calculated as the secant to the backbone curve at $0.7 V_{p}$. The ultimate drift capacity of the curve is defined as the drift corresponding to a force degradation equal to $20 \%$ of $V_{p}$. When such a degradation was not observed before the end of the test, the ultimate drift was computed as an average of the largest drifts reached by the wall in the positive and negative loading direction (in case of TUD COMP 5, only negative loading was considered). The ultimate shear force, corresponding to the horizontal branch of the curve, is determined by imposing that the area below the backbone curve and the equivalent bilinear curve up to the ultimate drift are equal. The bilinear curves were initially computed for both loading directions (Fig. 4), and average values were then derived. Figure 9 shows the average equivalent bilinear curves. Table 5 reports the parameters of the bilinear curves, along with the ratio between the peak and the ultimate shear force $V_{u} / V_{p}$ and the ultimate ductility of the system $\mu_{u}$, defined as the ratio between the ultimate drift capacity 

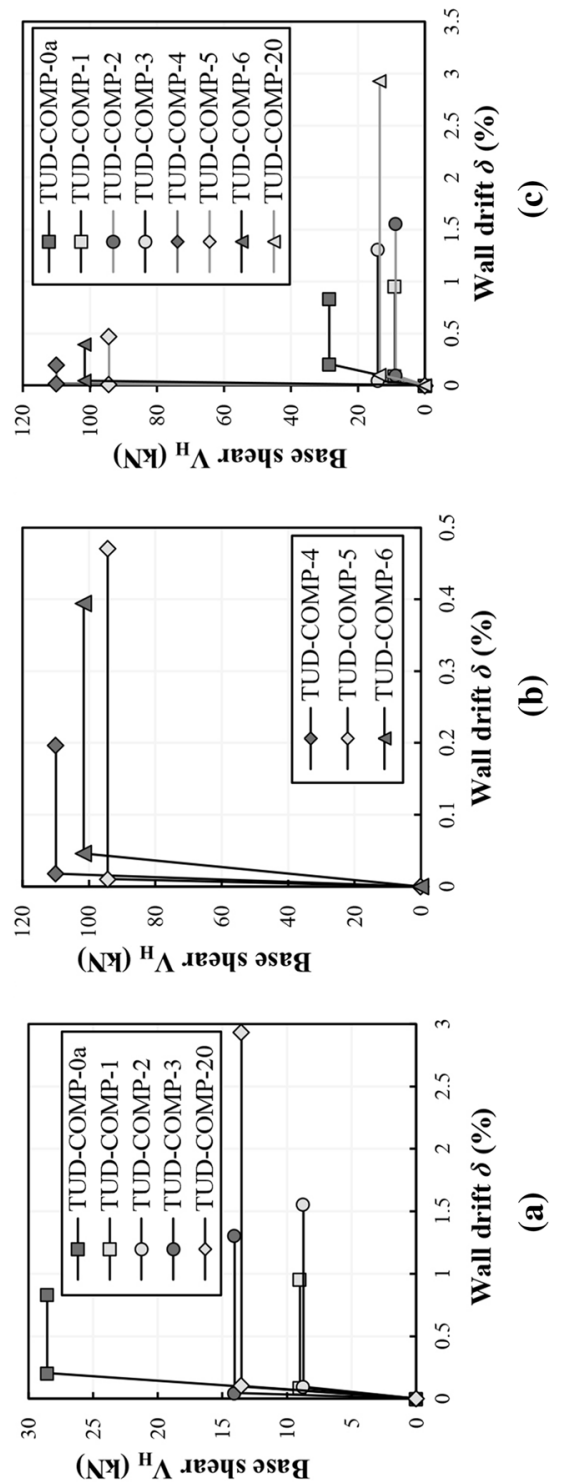

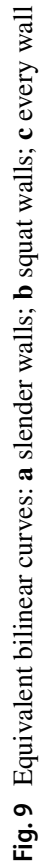


and the elastic drift $\delta_{e l}=V_{u} / k_{e f f}$. The ultimate shear can be on average well approximated by the peak lateral force multiplied by the factor $0.94(C V=2.9 \%)$. This value is exactly the same as measured by Salmanpour et al. (2015) and also close to the factor 0.90 proposed by Tomaževič (1999) for walls failing in shear only. In this respect, no difference was observed depending on the observed failure mode.

\section{Discussion}

In this section the results of the experimental tests are discussed in terms of initial stiffness, base shear force capacity, deformation capacity, and equivalent hysteretic damping.

\subsection{Initial stiffness}

For each test, the initial stiffness of the wall $k_{i n}$ was computed as the slope of the secant line connecting the maximum and minimum extreme points of the loop during the first run of the first cycle (that corresponded approximately to $20 \%$ of the peak base shear). Even though different values of the initial stiffness were measured even for specimens with the same geometry and boundary conditions, negative dependence of the initial stiffness on the shear ratio was observed (the linear regression line computed between the reciprocal of $k_{i n}$ and the shear ratio $h_{w 0} / l_{w}$ is highlighted in Fig. 10a).

The initial stiffness of a wall can be predicted by the elastic stiffness $k_{e l}$ computed according to the Timoshenko beam theory:

$$
k_{e l}=\frac{1}{\frac{h_{w}^{3}}{\alpha E I_{w}}+\frac{h_{w}}{\kappa A_{w} G}}
$$

where $h_{w}$ is the height of the wall, $A_{w}$ and $I_{w}$ are the wall section's area and moment of inertia, respectively, $\kappa$ the Timoshenko shear coefficient (equal to $5 / 6$ for rectangular sections),

Table 5 Parameters of the equivalent bilinear curves

\begin{tabular}{lcrllr}
\hline Specimen name & $\begin{array}{l}k_{\text {eff }} \\
\mathrm{kN} / \mathrm{mm}\end{array}$ & \multicolumn{1}{c}{$\begin{array}{c}V_{u} \\
\mathrm{kN}\end{array}$} & $\begin{array}{l}\delta_{u} \\
\%\end{array}$ & $\begin{array}{l}V_{u} / V_{p} \\
\%\end{array}$ & \multicolumn{1}{c}{$\begin{array}{l}\mu_{u} \\
-\end{array}$} \\
\hline TUD-COMP-0a & 6.3 & 28.5 & 0.83 & 98 & 5.0 \\
TUD-COMP-1 & 3.9 & 9.1 & $0.95^{\mathrm{a}}$ & 94 & 10.4 \\
TUD-COMP-2 & 3.6 & 8.7 & $1.56^{\mathrm{a}}$ & 97 & 17.8 \\
TUD-COMP-3 & 11.2 & 14.0 & 1.31 & 96 & 28.9 \\
TUD-COMP-4 & 222.8 & 110.0 & 0.20 & 96 & 11.1 \\
TUD-COMP-5 & 305.9 & 94.3 & $0.47^{\mathrm{b}}$ & 92 & 46.3 \\
TUD-COMP-6 & 80.4 & 101.6 & 0.39 & 93 & 8.5 \\
TUD-COMP-20 & 4.8 & 13.5 & 2.93 & 89 & 28.8 \\
\hline
\end{tabular}

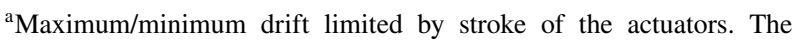
reported value represents a lower bound of the ultimate drift of the wall

${ }^{b}$ Maximum drift limited by instability of the system. The reported value is computed for negative loads only 
$\alpha$ is a coefficient that describes the wall boundary conditions (equals to 3 for cantilever and to 12 for double clamped conditions), $\mathrm{E}$ and $\mathrm{G}$ the elastic and shear modulus of masonry (the equation disregards the orthotropic nature of masonry). The Young's modulus $E$ was provided by the companion material tests, and assumed equal to the direction perpendicular to the bed-joints at $10 \%$ of the compressive strength ( $E_{2}$ in Table 2$)$. The shear modulus $G$ was taken as $0.4 E$, as recommended in EN 1996-1 (CEN 2005a). The elastic stiffness was compared to the experimental initial stiffness $k_{i n}$, as shown in Fig. 10b: the values of the elastic stiffness $k_{e l}$ slightly underestimate on average the experimental initial stiffness $k_{i n}$, and the dispersion of the results $(C V=0.25)$ was in line with the large scatter of values for the Young's modulus $E_{2}$ as obtained at material level from the compression tests (Table 2). It is then concluded that the assumed ratio $G / E=0.4$ is reasonable. A summary of the elastic, initial, and effective stiffness is listed in Table 6.

As discussed in the previous section, the effective stiffness $k_{\text {eff }}$ of an equivalent bilinear curve is evaluated as the secant stiffness computed at $70 \%$ of the peak lateral force. At the same time, standards and guidelines commonly suggest to estimate the stiffness of an equivalent bilinear curve as a reduced value of the elastic stiffness $k_{e l}$ (usually $50 \%$ of $k_{e l}$ ). Figure 11 a shows a comparison between the effective stiffness $k_{e f f}$ derived from the experimental tests and the elastic stiffness $k_{e l}$. On average, the use of $50 \%$ of $k_{e l}$ leads to an underestimation of $k_{\text {eff }}$. However, the results are very dispersed $(C V=0.58)$, mainly influenced by the high effective stiffness of the two double clamped squat walls (TUD-COMP-4 and TUD-COMP-5). In fact, the degradation of the wall stiffness $k$ at increasing values of the wall drift was slower for squat walls than for slender walls, as shown in Fig. 11b. For this reason, the effective stiffness may be assumed to be a larger fraction of $k_{e l}$ for squat walls (approximately when $h_{w 0} / l_{w}<1$ ), whereas the use of $50 \%$ of $k_{e l}$ seems more appropriate for slender walls $\left(h_{w 0} / l_{w}>1\right)$. The small number of tests and the dispersion of the results do not allow to draw more precise conclusions. In fact, the performed tests showed that the reduction of the elastic stiffness by a factor often

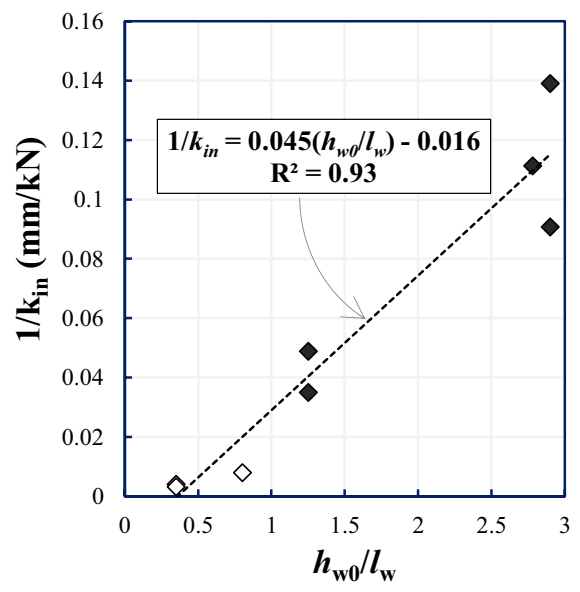

(a)

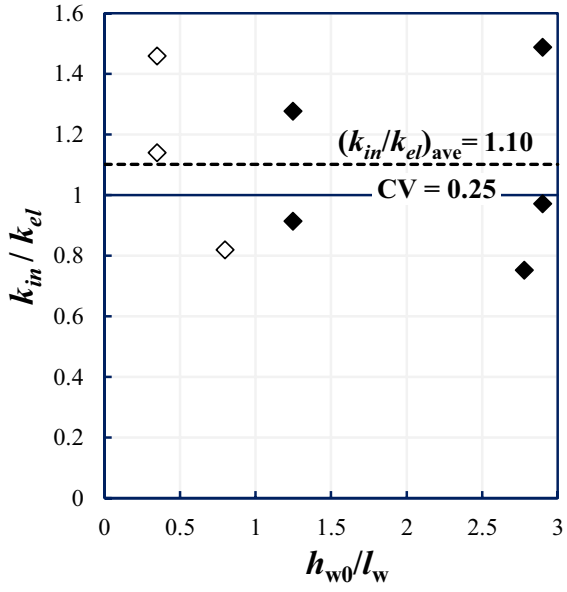

(b)

Fig. 10 Relationship between the initial stiffness and the shear ratio (a), and ratio between the initial stiffness $k_{i n}$ and the estimated elastic stiffness $k_{e l}(\mathbf{b})$. Black diamonds stand for slender walls, and white diamonds for squat walls 
Table 6 Elastic, initial, and effective stiffness of the tested walls

\begin{tabular}{llrlll}
\hline Specimen name & $\begin{array}{l}k_{\text {in }} \\
\mathrm{kN} / \mathrm{mm}\end{array}$ & $\begin{array}{l}k_{\text {eff }} \\
\mathrm{kN} / \mathrm{mm}\end{array}$ & $\begin{array}{l}k_{e l} \\
\mathrm{kN} / \mathrm{mm}\end{array}$ & $\begin{array}{l}k_{i n} / k_{e l} \\
-\end{array}$ & $\begin{array}{l}k_{e f f} / k_{e l} \\
-\end{array}$ \\
\hline TUD-COMP-0a & 28.6 & 6.3 & 22.5 & 1.27 & 0.28 \\
TUD-COMP-1 & 7.2 & 3.9 & 7.4 & 0.97 & 0.53 \\
TUD-COMP-2 & 11.0 & 3.6 & 7.4 & 1.49 & 0.49 \\
TUD-COMP-3 & 20.5 & 11.2 & 22.5 & 0.91 & 0.50 \\
TUD-COMP-4 & 247.8 & 222.8 & 217.5 & 1.14 & 1.02 \\
TUD-COMP-5 & 317.2 & 305.9 & 217.5 & 1.46 & 1.41 \\
TUD-COMP-6 & 126.4 & 80.4 & 154.4 & 0.82 & 0.52 \\
TUD-COMP-20 & 9.0 & 4.8 & 12.0 & 0.75 & 0.40 \\
\hline
\end{tabular}

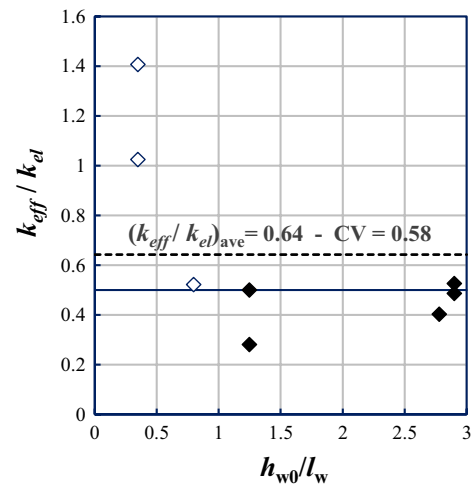

(a)

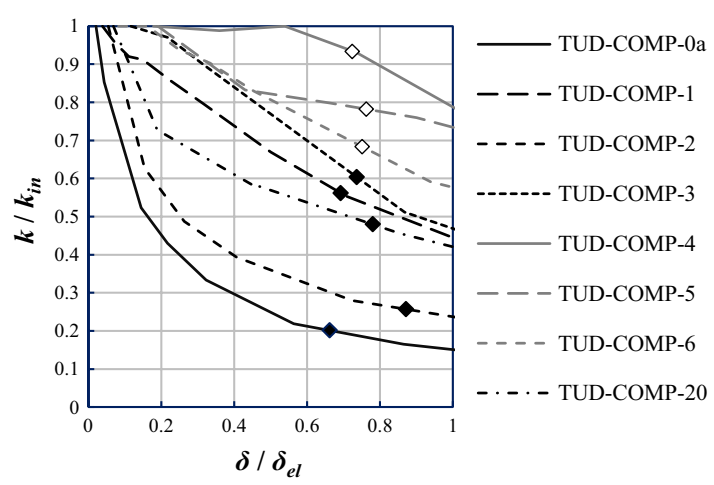

(b)

Fig. 11 Ratio between the effective stiffness and the estimated elastic stiffness (a), and values of the wall stiffness $k$ normalised with respect to $k_{i n}$ at increasing values of the wall drift $\delta$ normalised with respect to $\delta_{e l}(\mathbf{b}) . k$ is computed as the secant stiffness at increasing values of $\delta / \delta_{e l}$. The black (slender walls) and white (squat walls) diamonds correspond to the point at which the effective stiffness is computed

fails to provide an accurate estimate of the wall effective stiffness. It is important to note that an inaccurate estimate of the effective stiffness of the equivalent bilinear curve may have a relevant impact on the assessment of URM structures at both serviceability and ultimate limit states.

\subsection{Base shear force capacity}

Several models have been proposed in literature to estimate the maximum shear force capacity of URM walls (e.g. Turnšek and Čačovič 1971; Mann and Muller 1982), usually on the basis of wall geometry, boundary conditions and masonry material properties such as cohesion, friction coefficient, and compressive strength. These models can estimate the wall force capacity with satisfactory accuracy, and represent the basis for the methods recommended in international standards. The equations in the European EN 1998-3 (CEN 2005b) and Dutch NPR 9998 (NEN 2018) standards are summarised in Table 7. However, reliable measurements of the masonry material properties 
Table 7 Shear force capacity and near collapse (NC) drift capacity as computed by EN 1998-3 and NPR 9998

\begin{tabular}{|c|c|c|c|}
\hline Standard & Failure mode & Shear force capacity & NC drift capacity \\
\hline \multirow[t]{2}{*}{ EN 1998-3 } & Shear failure & $\begin{array}{l}V_{s}=f_{v d} l_{w}^{\prime} t_{w} \\
\text { with: } \\
\qquad f_{v d}=f_{v 0}+0.4 \sigma_{v} l_{w} / l_{w}^{\prime} \leq 0.065 f_{b}\end{array}$ & $\frac{4}{3} \cdot 0.4 \%$ \\
\hline & Flexural failure & $V_{f}=\frac{l_{w} N}{2 h_{w 0}}\left(1-1.15 \frac{\sigma_{v}}{f_{c}}\right)$ & $\frac{4}{3} \cdot 0.8 \%\left(\frac{h_{w 0}}{l_{w}}\right)$ \\
\hline \multirow[t]{2}{*}{ NPR 9998} & Shear failure & $\begin{array}{l}V_{s}^{(1)}=\left(f_{v 0}+\mu \sigma_{v}\right) l_{w}^{\prime} t_{w} \\
V_{s}^{(2)}=0.1 f_{b} l_{w}^{\prime} t_{w}\end{array}$ & $\begin{array}{l}0.75 \% \\
1.35 \%\left(1-2.6 \frac{\sigma_{v}}{f}\right) \frac{h_{r e f}}{h} \sqrt{\frac{h_{w}}{l}}\end{array}$ \\
\hline & Flexural failure & $V_{f}=\frac{l_{w} N}{2 h_{w 0}}\left(1-1.15 \frac{\sigma_{v}}{f_{c}}\right)$ & with $h_{r e f}=2.4 \mathrm{~m}$ \\
\hline
\end{tabular}

$V_{s}, V_{f}=$ base shear force capacity predicted by standards for shear and flexural failure, respectively; $N=$ total compressive load on top of the wall; $h_{w}=$ height of the wall; $h_{w 0}=$ effective height of the wall; $h_{r e f}=$ reference height of the wall (equal to $2.4 \mathrm{~m}$ ); $l_{w}=$ length of the wall; $l_{\mathrm{w}}$ ' =length of the uncracked section at the base of the wall; $t_{w}=$ thickness of the wall; $f_{b}=$ normalized compressive strength of masonry units; $f_{c}=$ compressive strength of masonry; $f_{v d}=$ design shear strength of masonry; $f_{v 0}=$ initial shear strength of masonry;; $\mu=$ friction coefficient; $\sigma_{v}=$ average vertical stress

are often not available, and when values suggested in national annexes and standards are used, these will not always precisely correspond to the actual in situ properties.

Magenes and Calvi (1997) already noted that, irrespective of the observed failure mode, the product of the reciprocal of the mean shear strength at peak $\left(f_{v p}=V_{p} /\left(l_{w} t_{w}\right)\right)$ and the average ultimate shear strength $\left(f_{v u}=f_{v 0}+\mu \sigma_{v}\right)$, increases linearly with the shear ratio. However, the identified relation depends once again on the masonry material properties. A similar relation is observed also in Fig. 12a; however, no material parameters appear in this case, since the linear relation is set between the shear ratio and the reciprocal of the mean shear strength at peak $f_{v u}$ multiplied by the average vertical stress $\sigma_{v}$ only. Hence, an empirical relationship that can be applied irrespective of the expected failure mode of the wall and that does not require the input of any material properties is hereafter proposed:

$$
V_{p}=\frac{\sigma_{v} l_{w} t_{w}}{A\left(\frac{h_{w 0}}{l_{w}}\right)+B}=\frac{N}{A\left(\frac{h_{w 0}}{l_{w}}\right)+B}=\frac{N}{1.65\left(\frac{h_{w 0}}{l_{w}}\right)+0.8}
$$

where $\sigma_{v}$ is the applied vertical pre-compression stress, $l_{w}$ and $t_{w}$ are the length and the thickness of the wall, respectively, $N$ is the total compressive load acting on top of the wall, $h_{w 0}$ is the effective height of the wall, and $A$ and $B$ are two constants $(A=1.65 ; B=0.8)$ calibrated via linear regression analysis on the basis of the presented experimental results with the exclusion of specimen TUD-COMP-1 (white diamond in Fig. 12a), whose strength base shear force capacity was considerably lower than any analytical estimate (this test was anyhow included in the following assessment procedure). When the values $\mathrm{A}=2$ and $\mathrm{B}=0$ are used, the equation provides a upper limitation to the flexural capacity of the walls.

The validity of the proposed simplified formulation was assessed by considering a more extensive dataset of CS masonry walls, including not only tests performed on other CS brick masonry walls (Salmanpour et al. 2015; Graziotti et al. 2016a), but also on CS block masonry walls (Magenes et al. 2008; Fehling et al. 2008; Zilch et al. 2008; Ötes and Löring 2003; Mojsilovic 2011), and on CS element masonry walls (Esposito and Ravenshorst 


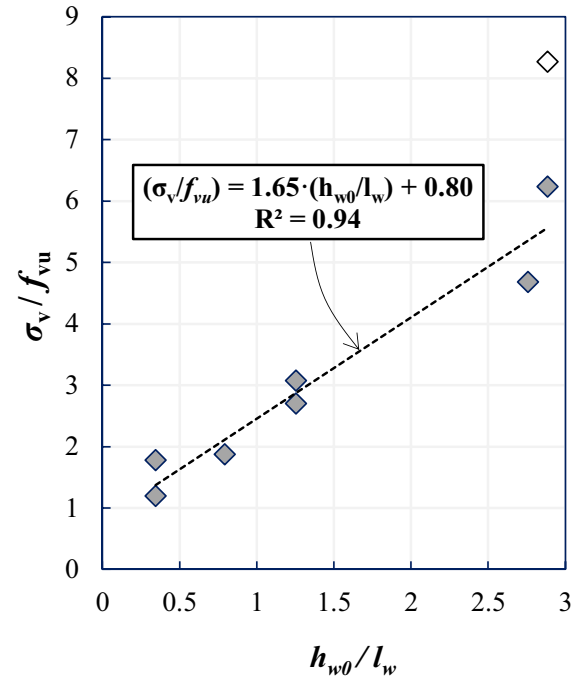

(a)

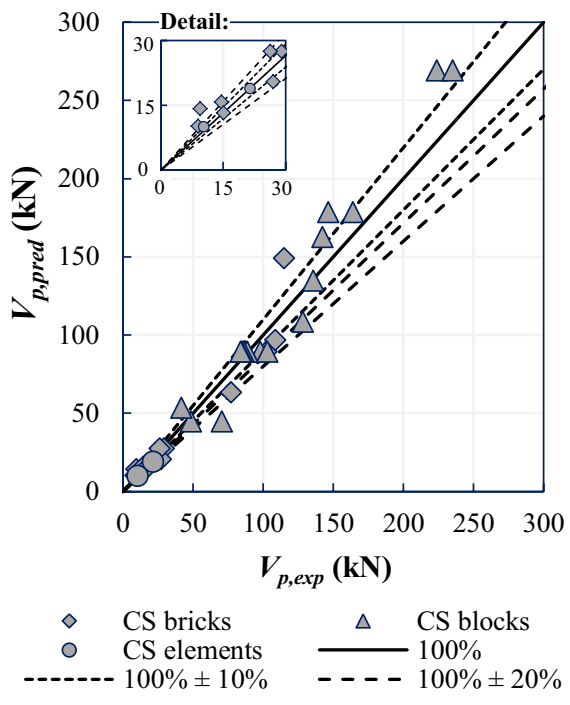

(b)

Fig. 12 Influence of the shear ratio on the peak shear strength of the tested walls and calibration of Eq. (2) (a). Comparison between the force capacity predicted according to Eq. (2) and the experimental values for an extended dataset of tests (detail for low peak loads in the inset) (b)

2017). When the data related to the tests were not available from the original documents, they have been complemented with the information collected by Morandi et al. (2018). In total a set of 31 tests was considered. It should be noted that, whereas the specimens presented in this paper had comparable material properties, the frictional properties of CS brick, block, and element masonry may differ substantially. However, there is a lack of experimental tests on CS element masonry walls with low aspect ratio and hence failing in shear. A summary of the geometrical and material properties of the walls included in the dataset, and of the experimental and estimated peak lateral force are presented in the Appendix. Figure 12b shows the relationship between the experimental peak shear force $V_{p}$ and the corresponding value predicted according to Eq. (2), $V_{p, p r e d}$. With few exceptions, the predicted peak shear force is close to the corresponding experimental one within an error of $\pm 20 \%$. The accuracy does not depend on the observed failure mode or on the type of CS units. Figure 13 compares the predictions obtained according to Eq. (2) to those obtained according to the equations recommended in EN 1998-3 and NPR 9998. For the two standards the material properties derived by the companion tests were used. The results obtained via the proposed equation are comparable to those computed according to the two standards for both the tested specimens (Fig. 13a) and the extended dataset (Fig. 13b). Although it is useful to predict the failure mode of a URM wall, for instance to determine its lateral drift capacity according to many standards, the proposed empirical equation does not provide this piece of information. For this reason, and since the relatively small number of tests that could be considered for the validation, the proposed equation may be used as a preliminary estimate of the wall lateral strength when no or limited data on the CS brick masonry material properties are available, especially in case of fast assessments or for prioritisation of interventions. 


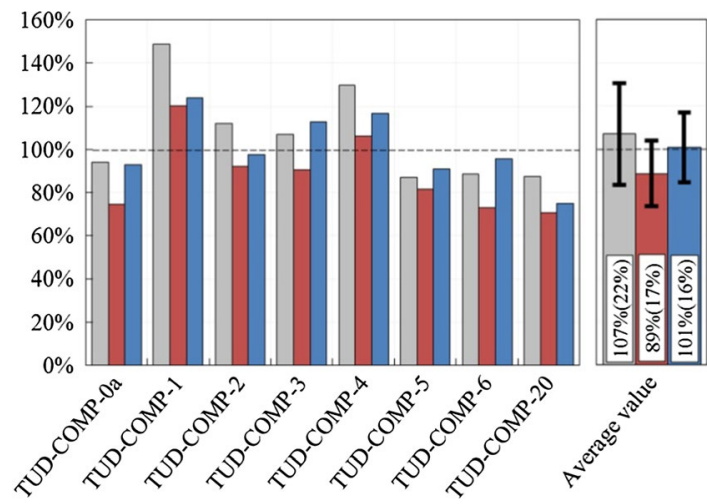

$\square$ Proposed formulation $\square$ EN 1998-3 formulation $\square$ NPR 9998 formulation

(a)

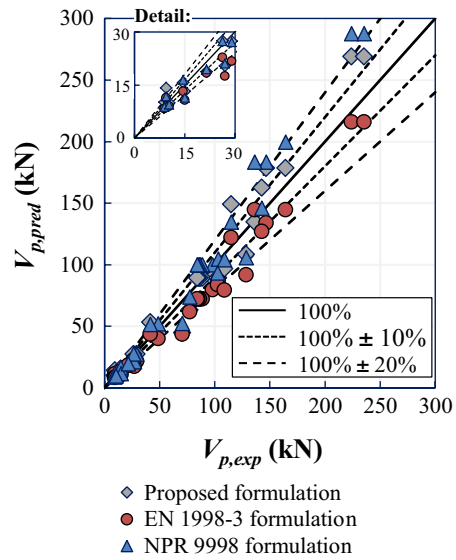

(b)

Fig. 13 Comparison between the force capacity predicted for the tested specimens (a) and for an extended dataset of tests (detail for low peak loads in the inset) (b) according to Eq. (2) and to EN 1998-3 or NPR 9998 formulations

\subsection{Deformation capacity}

The deformation capacity of a wall is commonly defined by the drift at near collapse (NC). Even though there is no complete agreement within the scientific community on the identification of the NC drift, many works (e.g. Salmanpour et al. 2015; Esposito and Ravenshorst 2017; Messali and Rots 2018) estimated it as the drift corresponding to 20\% of force degradation. The NC drift was determined in this work according to this approach, thus corresponding to the ultimate drift of the equivalent bilinear curve. The NC drifts of the tested walls are reported in Table 5 and plotted in Fig. 14a against the shear ratio. A clear dependency on the observed failure mode and on the shear ratio is observed. However, a more detailed discussion on the NC drift capacity of the walls is not included in this work, since it depends on several factors and the number of tested walls is not large enough to allow for a statistical analysis of the problem. A comprehensive analysis of the NC drift of rocking CS walls (as well as of clay brick walls), including those presented in this work, is discussed by Messali and Rots (2018). The outcomes of that study were also used to come up with a calibrated empirical equation used in NPR 9998 (NEN 2018) for estimating the deformation capacity of rocking walls.

Similar to the approach adopted for the force capacity, the observed NC drifts were compared to the predictions obtained according to Eurocode 8-part 3 (CEN 2005b) and NPR 9998 (NEN 2018). The equations recommended by the two standards are summarised in Table 7. A summary of the results is listed in Table 8, and a comparison between the experimental and predicted results is shown in Fig. 14b. For walls failing in shear, non-conservative estimates of the drift capacity are obtained according to both the standards. The error is larger adopting the value recommended in NPR 9998, since that value is higher than the value prescribed in EC8-3 (0.75\% vs. 0.53\%), while the walls showed limited ductility during the experimental tests. However, past experimental tests (Beyer and Mergos 2015) and numerical simulations (Wilding et al. 2017) showed that the deformation capacity of walls failing in shear decreases with the number of applied cycles, and this fact may partially explain the large NC drift recommended in the Dutch guideline, which 


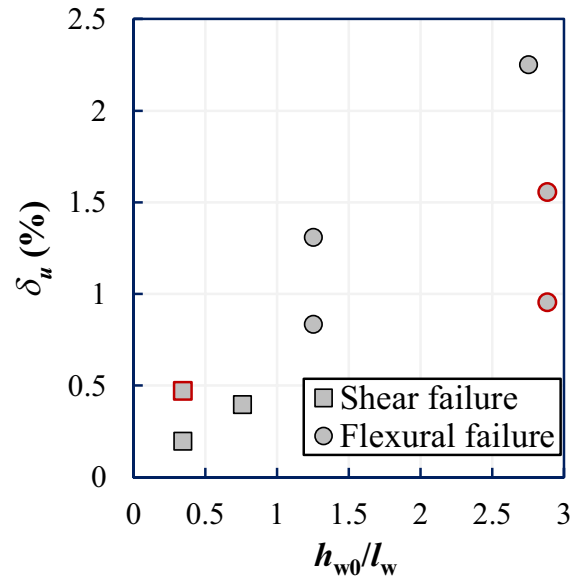

(a)

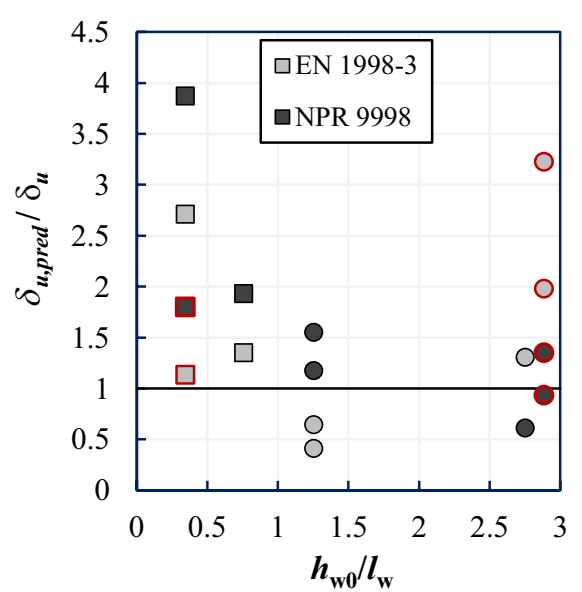

(b)

Fig. 14 Experimental NC drift of the tested walls, and comparison with the predictions by EN 1998-3 and NPR 9998 (walls failing in shear are represented by square markers, walls failing in flexure by round markers). The walls whose ultimate drift could not be reached due to limitations of the test setup are identified by red markers

was developed specifically for an area characterised by low/moderate seismicity and shortduration earthquakes. For walls failing in flexure, more accurate predictions are obtained, particularly when the equation suggested in NPR 9998 is used. This is consistent with the fact that the equation included in NPR 9998 was derived on the basis of a dataset including also the tests presented in this paper. However, it should be also considered that the ultimate drift capacity of specimens TUD-COMP-1 and TUD-COMP-2 could not be reached due to limitations of the setup. In these two cases the large overestimation obtained according to EC8-3 would likely reduce if the tests could continue for larger displacements. In conclusion, in case of flexural failure the application of the equation recommended in the Dutch standard returns better estimates than those obtained according to EN 1998-3, whereas for shear failure a reduction of the expected NC drift capacity may be suggested, even though further investigation to consider the effect of short duration earthquakes is advised.

\subsection{Equivalent hysteretic damping}

The dissipated hysteretic energy was evaluated in terms of the equivalent hysteretic damping coefficient $\xi_{\text {hyst }}$ as originally defined by Jacobsen (1960):

$$
\xi_{h y s t}=\frac{W_{i}}{2 \pi\left(W_{e l}^{+}+W_{e l}^{-}\right)}
$$

where, for each run, $W_{i}$ is the dissipated energy, and $W_{e l}^{+}$and $W_{e l}^{-}$are the elastic energy for positive and negative displacements, respectively, computed as the product of maximum/ minimum peak displacement and force of the run. 
Table 8 Summary of the ratios between the predictions by EN 1998-3 and NPR 9998 and the experimental drift capacity $\left(\delta_{u, p r e d} / \delta_{u}\right)$. The values of the standard deviation are reported in brackets

\begin{tabular}{llll}
\hline & Every failure mode & Shear failure mode & Flexural failure mode \\
\hline EN 1998-3 & $1.54(0.98)$ & $1.61(0.92)$ & $1.50(1.12)$ \\
NPR 9998 & $1.59(0.98)$ & $2.36(1.28)$ & $1.12(0.38)$ \\
\hline
\end{tabular}

Figure 15 shows the equivalent hysteretic damping coefficient $\xi_{\text {hyst }}$ computed at increasing values of the ductility of the wall per each cycle $\mu_{c y c l e}$, computed as the ratio between the wall drift $\delta$ and the elastic drift $\delta_{e l}$. As already observed by Magenes and Calvi (1997), the dissipated energy increases along with the damage and is related to the failure mechanism. The squat walls, characterised by shear failure, reached high values of equivalent damping. The obtained maximum dissipated energy and damping were similar for the three squat walls $\left(40 \%<\xi_{\max }<50 \%\right)$, even though slightly larger values were computed when the sliding occurred along a single bed-joint at the base of the wall, such as in specimen TUD-COMP-5. On the other hand, for the slender walls, characterised by rocking behaviour, smaller damping values were obtained. For the two slender double clamped walls (TUD-COMP-0a and TUD-COMP-3) the damping values in the last cycles were larger than for the cantilever walls, since both top and bottom ends of the walls were subjected to damage. The measured values of the damping coefficient were in line with those observed on recent tests on CS brick masonry walls (Graziotti et al. 2016a), but significantly higher than the ones reported from tests on CS blocks masonry walls (Magenes et al. 2008). In fact, in the present study, dissipative mechanisms such as the opening of short diagonal cracks, the compressive splitting of the bricks, and the sliding along the mortar joints were observed even for walls whose failure was mainly governed by rocking.

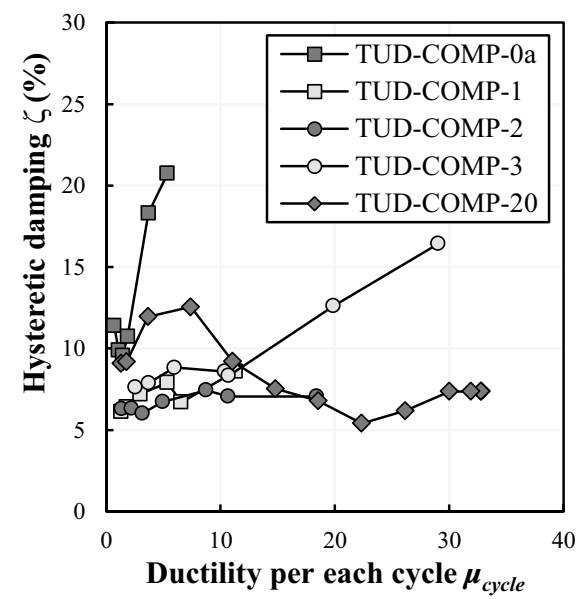

(a)

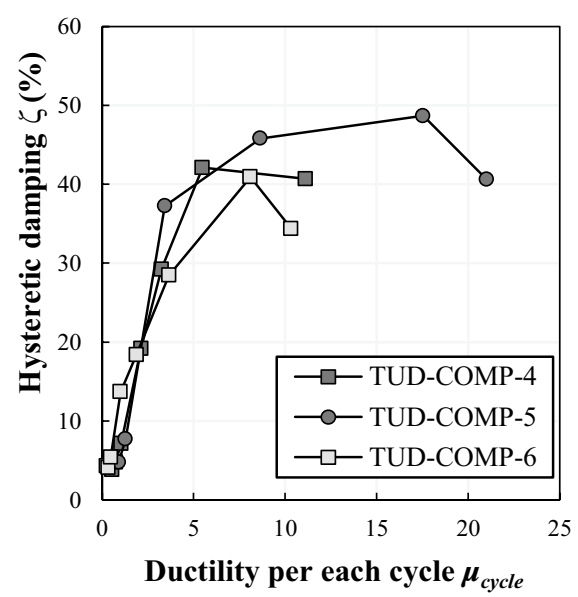

(b)

Fig. 15 Hysteretic damping at increasing values of ductility per cycle for a slender and $\mathbf{b}$ squat walls 


\section{Conclusions}

This paper presents the outcomes of an experimental investigation consisting of eight quasi-static cyclic tests performed on full-scale CS brick masonry walls. This masonry type was widely used in dwellings built between 1960 and 1980 in the province of Groningen (north of the Netherlands), an area now subjected to induced seismicity. The structural performance of this material has received only little attention in the past. The campaign investigated the hysteretic behaviour of the walls under a combination of vertical and lateral in-plane load. Different dimensions, boundary conditions, and applied pre-compression loads were considered.

The test results showed the relevance of the shear ratio on the wall response. The prevailing failure mode depended mainly on the shear ratio, with flexure governing for high shear ratios, and shear failure occurring for low shear ratios. Clear relationships were observed also with respect to the initial stiffness (negative relationship) and to the displacement capacity and the peak lateral force (both approximately linear). With regards to the initial stiffness of the tested walls, on one hand the performed tests showed that it can be fairly approximated by the elastic stiffness computed according to the Timoshenko beam theory (as often recommended by international standards due to its simplicity) and assuming the shear modulus being equal to $40 \%$ of the Young's modulus. On the other hand, the tests illustrated the difficulty of providing accurate estimates of the wall effective stiffness (which has a relevant impact on the assessment of URM structures at both serviceability and ultimate limit states) due to the different degradation of the wall stiffness at increasing drift values from case to case. Nevertheless, acceptable results were achieved for most of the tested slender walls when the effective stiffness was estimated as $50 \%$ of the elastic stiffness.

More accurate predictions were obtained for the wall peak shear force. However, the equations recommended in international standards commonly require the identification of material properties (such as cohesion, friction coefficient, and compressive strength), which are often not easy to be estimated or measured via in situ tests. For this reason, the paper proposes an empirical equation that does not need the input of any material parameter and can be applied irrespective of the expected failure mode of the wall. The equation was calibrated against the presented tests and its accuracy assessed against an extended dataset of 31 experimental tests all performed on CS masonry walls. The predictions obtained via the proposed equation had a level of accuracy comparable to that computed according to EN 1998-3 and NPR 9998. Therefore, the proposed equation may be used to obtain a preliminary estimate of the wall peak shear force when no or limited data on the CS masonry material properties are available, especially in case of fast assessments or to prioritisation of interventions, but should not be used to conduct an accurate assessment.

The displacement capacity of the walls at near collapse was not predicted accurately by the equations included in the two standards (the European EN 1998-3 and the Dutch NPR 9998) that are usually adopted by professionals to assess the seismic capacity of Dutch CS brick masonry buildings, although it is important to note that two tests were stopped before the wall could reach the NC displacement due to limitations of the 
setup. In case of flexural failure the application of the recommendations provided in NPR 9998 returns more accurate estimates than those obtained according to EN 19983. This is consistent with the fact that the equation included in NPR 9998 was derived on the basis of a dataset including also the tests presented in this paper. On the other hand, in case of shear failure a reduction of the expected NC drift capacity would return more accurate predictions, even though further investigation to consider the effect of the applied loading protocol is advised (for instance with a reduced number of loading cycles).

The tests allowed also to evaluate the energy dissipated during each loading cycle in terms of the equivalent hysteretic damping coefficient. Moderate (for slender walls) to high (for squat walls) values were computed. The values are in line with those obtained from other recent tests on CS brick masonry walls, but significantly larger than the ones reported for tests on CS blocks masonry.

Overall, the testing campaign allowed to characterise the in-plane behaviour of CS brick masonry walls under the combination of vertical and cyclic lateral loads. Besides, the reported results can be used to validate numerical and analytical models, with particular devotion to the seismic assessment of terraced and detached houses built in 1960-1980 in the north of the Netherlands.

\section{Access to experimental data}

The experimental results of the presented test are available via the repository 4TU. ResearchData at https://doi.org/10.4121/uuid:27d24c66-1bd0-4e6d-86dd-4a4b8871d8d8. The data are distributed under the license type CC BY.

Acknowledgements The research were funded by Nederlandse Aardolie Maatschappij (NAM), under the contract numbers UI46268 ("Physical testing and modelling-Masonry structures Groningen"), and UI63654 ("Testing program 2016 for Structural Upgrading of URM Structures"), which is gratefully acknowledged. Part of this research was developed in cooperation with the engineering company ARUP and the European Centre for Training and Research in Earthquake (Eucentre).

Open Access This article is licensed under a Creative Commons Attribution 4.0 International License, which permits use, sharing, adaptation, distribution and reproduction in any medium or format, as long as you give appropriate credit to the original author(s) and the source, provide a link to the Creative Commons licence, and indicate if changes were made. The images or other third party material in this article are included in the article's Creative Commons licence, unless indicated otherwise in a credit line to the material. If material is not included in the article's Creative Commons licence and your intended use is not permitted by statutory regulation or exceeds the permitted use, you will need to obtain permission directly from the copyright holder. To view a copy of this licence, visit http://creativecommons.org/licenses/by/4.0/.

\section{Appendix}

See Tables 9, 10. 


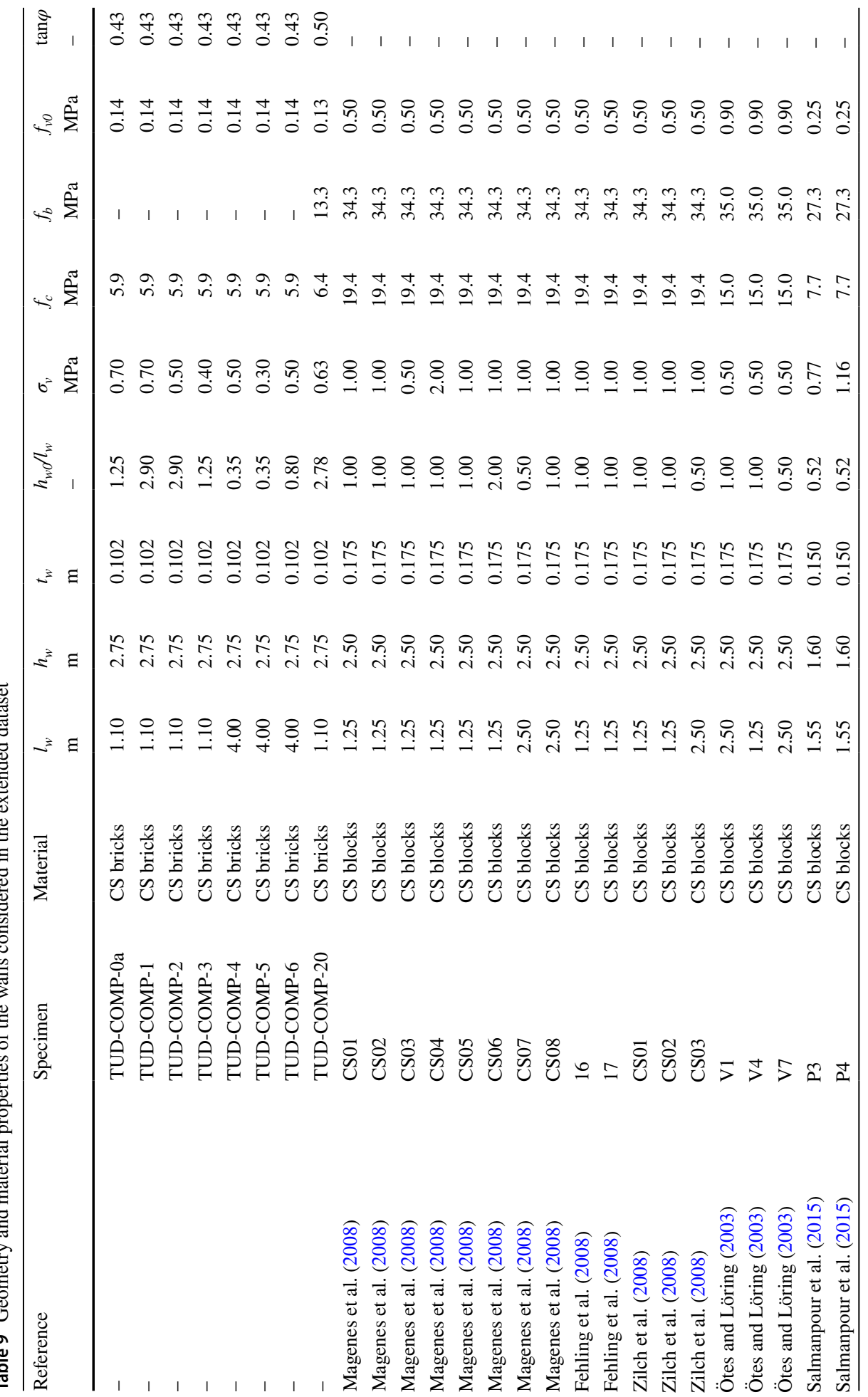




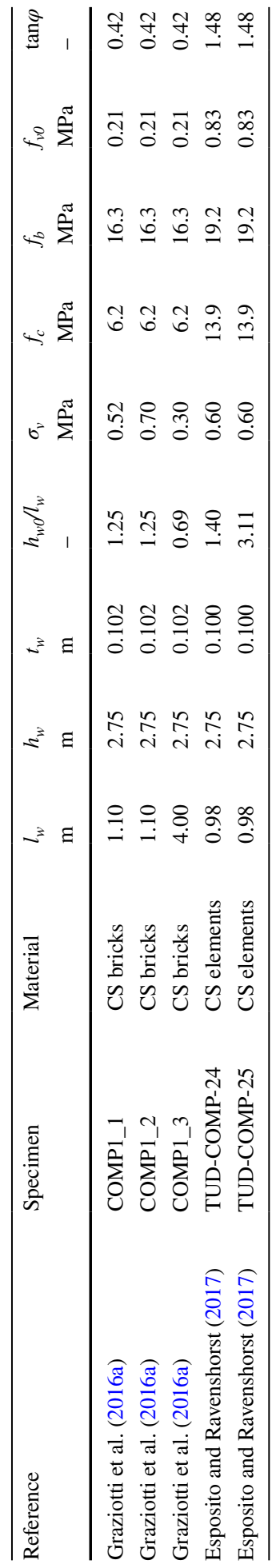


Table 10 Experimental peak lateral force, and loads predicted according to the proposed empirical equation, and the sets of equation recommended in EN 1998-3 and NPR 9998 for the walls considered in the extended dataset

\begin{tabular}{|c|c|c|c|c|c|}
\hline \multirow[t]{4}{*}{ Reference } & \multirow[t]{4}{*}{ Specimen } & \multicolumn{4}{|c|}{ Peak lateral force } \\
\hline & & Experimental & Proposed & EN 1998-3 & NPR 9998 \\
\hline & & $V_{p, \exp }$ & $V_{p, p r e d}$ & $V_{p, p r e d}$ & $V_{p, p r e d}$ \\
\hline & & $\mathrm{kN}$ & $\mathrm{kN}$ & $\mathrm{kN}$ & $\mathrm{kN}$ \\
\hline - & TUD-COMP-0a & 29.1 & 27.4 & 21.7 & 27.0 \\
\hline - & TUD-COMP-1 & 9.5 & 14.1 & 11.4 & 11.8 \\
\hline - & TUD-COMP-2 & 9.0 & 10.1 & 8.3 & 8.8 \\
\hline- & TUD-COMP-3 & 14.6 & 15.6 & 13.2 & 16.5 \\
\hline - & TUD-COMP-4 & 115.0 & 149.0 & 122.1 & 134.4 \\
\hline- & TUD-COMP-5 & 102.5 & 89.4 & 83.9 & 93.3 \\
\hline- & TUD-COMP-6 & 108.9 & 96.7 & 79.5 & 104.0 \\
\hline- & TUD-COMP-20 & 15.1 & 13.2 & 10.7 & 11.3 \\
\hline Magenes et al. (2008) & CS01 & 85.6 & 89.3 & 72.3 & 99.7 \\
\hline Magenes et al. (2008) & $\mathrm{CS} 02$ & 87.0 & 89.3 & 72.3 & 99.7 \\
\hline Magenes et al. (2008) & $\mathrm{CS} 03$ & 48.5 & 44.6 & 39.9 & 52.0 \\
\hline Magenes et al. (2008) & CS04 & 146.6 & 178.6 & 133.8 & 183.2 \\
\hline Magenes et al. (2008) & $\mathrm{CS} 05$ & 98.0 & 89.3 & 79.8 & 99.7 \\
\hline Magenes et al. (2008) & CS06 & 41.6 & 53.4 & 43.5 & 51.4 \\
\hline Magenes et al. (2008) & CS07 & 224.1 & 269.2 & 216.0 & 287.5 \\
\hline Magenes et al. (2008) & CS08 & 164.3 & 178.6 & 144.6 & 199.4 \\
\hline Fehling et al. (2008) & 16 & 88.7 & 89.3 & 72.3 & 99.7 \\
\hline Fehling et al. (2008) & 17 & 86.3 & 89.3 & 72.3 & 99.7 \\
\hline Zilch et al. (2008) & $\mathrm{CS} 01$ & 84.5 & 89.3 & 72.3 & 99.7 \\
\hline Zilch et al. (2008) & $\mathrm{CS} 02$ & 84.0 & 89.3 & 72.3 & 99.7 \\
\hline Zilch et al. (2008) & $\mathrm{CS} 03$ & 235.5 & 269.2 & 216.0 & 287.5 \\
\hline Ötes and Löring (2003) & V1 & 103.0 & 89.3 & 87.1 & 104.4 \\
\hline Ötes and Löring (2003) & V4 & 70.5 & 44.6 & 43.5 & 52.2 \\
\hline Ötes and Löring (2003) & V7 & 136.0 & 134.6 & 144.6 & 183.3 \\
\hline Salmanpour et al. (2015) & $\mathrm{P} 3$ & 128.5 & 108.4 & 91.7 & 105.7 \\
\hline Salmanpour et al. (2015) & $\mathrm{P} 4$ & 142.6 & 162.6 & 127.0 & 145.8 \\
\hline Graziotti et al. (2016a) & COMP1_1 & 27.1 & 20.4 & 17.5 & 21.1 \\
\hline Graziotti et al. (2016a) & COMP1_2 & 26.4 & 27.4 & 22.7 & 27.3 \\
\hline Graziotti et al. (2016a) & COMP1_3 & 77.3 & 63.3 & 61.8 & 73.6 \\
\hline Esposito and Ravenshorst (2017) & TUD-COMP-24 & 21.6 & 18.8 & 18.4 & 19.4 \\
\hline Esposito and Ravenshorst (2017) & TUD-COMP-25 & 10.4 & 9.9 & 9.0 & 9.5 \\
\hline
\end{tabular}

\section{References}

Beyer K, Mergos P (2015) Sensitivity of drift capacities of URM walls to cumulative damage demands and implications on loading protocols for quasi-static cyclic tests. In: Proceedings of the 12th North American Masonry conference

Bruneau M (2002) Building damage from the Marmara, Turkey earthquake of August 17, 1999. J Seismol 6(3):357-377. https://doi.org/10.1023/A:1020035425531 
Ceci AM, Contento A, Fanale L, Galeota D, Gattulli V, Lepidi M, Potenza F (2010) Structural performance of the historic and modern buildings of the University of L'Aquila during the seismic events of April 2009. Eng Struct 32(7):1899-1924. https://doi.org/10.1016/j.engstruct.2009.12.023

CEN, European Committee for Standardisation (2005a) Eurocode 6: design of masonry structures-part 1-1: general rules for reinforced and unreinforced masonry structures. Design Code EN 1998-3. Brussels, Belgium

CEN, European Committee for Standardisation (2005b) Eurocode 8: design of structures for earthquake resistance-part 3: general rules, seismic actions and rules for buildings. Design Code EN 1998-3. Brussels, Belgium

Damiola M, Esposito R, Messali F, Rots JG (2018) Quasi-static cyclic out-of-plane tests on URM walls. In 10th International Masonry Conference (IMC). 9-11 July, Milan, Italy

EN 772-1 (2011) Methods of test for masonry units-part 1: determination of compressive strength

EN 1015-11 (1999) Methods of test for mortar for masonry-part 11: determination of flexural and compressive strength of hardened mortar

EN 1052-1 (1998) Method of test masonry-part 1: determination of compressive strength

EN 1052-3 (2002) Method of test masonry - part 3: determination of initial shear strength

EN 1052-5 (2005) Method of test masonry-part 5: determination of bond strength by bond wrench method

Esposito R, Ravenshorst GJP (2017). Quasi-static cyclic in-plane tests on masonry components 2016/2017. Delft University of Technology. Report number C31B67WP3-4, version 1, 10 August 2017

Esposito R, Terwel KC, Schipper RH, Ravenshorst GJP, Messali F, Rots JG (2017) Cyclic pushover test on an unreinforced masonry structure resembling a typical Dutch terraced house. In: Proceedings of 16th world conference of earthquake engineering (WCEE), Santiago, Chile

Esposito R, Messali F, Ravenshorst GJP, Schipper HR, Rots JG (2019) Seismic assessment of a labtested two-storey unreinforced masonry Dutch terraced house. Bull Earthq Eng. https://doi. org/10.1007/s10518-019-00572-w

Fehling E, Stuerz J, Emami A (2008) Test results on the behaviour of masonry under static (monotonic and cyclic) in plane lateral loads. Deliverable D7.1.a, ESECMaSE Project. Retrieved February 20, 2019, from https://www.esecmase.org

Graziotti F, Rossi A, Mandirola M, Penna A, Magenes G (2016a) Experimental characterization of calcium-silicate brick masonry for seismic assessment. In: Brick and block masonry: trends, innovations and challenges. Proceedings of the 16th international brick and block masonry conference, IBMAC, Padua, Italy

Graziotti F, Tomassetti U, Penna A, Magenes G (2016b) Out-of-plane shaking table tests on URM single leaf and cavity walls. Eng Struct 125:455-470. https://doi.org/10.1016/j.engstruct.2016.07.011

Graziotti F, Tomassetti U, Kallioras S, Penna A, Magenes G (2017) Shaking table test on a full scale URM cavity wall building. Bull Earthq Eng 15(12):5329-5364. https://doi.org/10.1007/s10518-017-0185-8

Graziotti F, Penna A, Magenes G (2018) A comprehensive in situ and laboratory testing programme supporting seismic risk analysis of URM buildings subjected to induced earthquakes. Bull Earthq Eng. https://doi.org/10.1007/s10518-018-0478-6

Graziotti F, Tomassetti U, Sharma S, Grottoli L, Magenes G (2019) Experimental response of URM single leaf and cavity walls in out-of-plane two-way bending generated by seismic excitation. Constr Build Mater 195:650-670. https://doi.org/10.1016/j.conbuildmat.2018.10.076

Jacobsen LS (1960) Damping in composite structures. In: Proceedings 2nd WCEE, Tokyo, vol 2, pp 1029-1044. Tokyo and Kyoto, Japan

Jafari S, Rots JG, Esposito R, Messali F (2017) Characterizing the material properties of Dutch unreinforced masonry. Procedia Eng 193:250-257. https://doi.org/10.1016/j.proeng.2017.06.211

Jafari S, Esposito R, Rots JG (2018) From brick to element: investigating the mechanical properties of calcium silicate masonry. In: Aguilar R, Torrealva D, Moreira S, Pando MA, Ramos LF (eds) Structural analysis of historical constructions. RILEM Bookseries, vol 18. Springer, Cham. https:// doi.org/10.1007/978-3-319-99441-3_64

Magenes G, Calvi GM (1997) In-plane seismic response of brick masonry walls. Earthq Eng Struct Dyn 26(11):1091-1112. https://doi.org/10.1002/(SICI)1096-9845(199711)26:11\%3C1091:AID-EQE69 3\%3E3.0.CO;2-6

Magenes G, Morandi P, Penna A (2008) In-plane cyclic tests of calcium silicate masonry walls. In: Proceedings of 12th international brick/block masonry conference, Sydney, Australia

Mann W, Muller H (1982) Failure of shear-stressed masonry. An enlarged theory, tests and application to shear walls. In: Proceedings British Ceramics Society, vol 30, p 223 
Messali F, Rots JG (2018) In-plane drift capacity at near collapse of rocking unreinforced calcium silicate and clay masonry piers. Eng Struct 164:183-194. https://doi.org/10.1016/j.engstruct.2018.02.050

Messali F, Ravenshorst GJP, Esposito R, Rots JG (2017). Large-scale testing program for the seismic characterization of Dutch masonry walls. In: Proceedings of 16th world conference on earthquake (WCEE), Santiago, Chile

Messali F, Esposito R, Jafari S, Ravenshorst GJP, Korswagen P, Rots JG (2018). A multiscale experimental characterisation of Dutch unreinforced masonry buildings. In: Proceeding of 16th European conference on earthquake engineering (ECEE), Thessaloniki, Greece

Mojsilović N (2011) Strength of masonry subjected to in-plane loading: a contribution. Int J Solids Struct 48(6):865-873. https://doi.org/10.1016/j.jjsolstr.2010.11.019

Morandi P, Albanesi L, Graziotti F, Piani TL, Penna A, Magenes G (2018) Development of a dataset on the in-plane experimental response of URM piers with bricks and blocks. Constr Build Mater 190:593-611. https://doi.org/10.1016/j.conbuildmat.2018.09.070

NEN, Nederlands Normalisatie Instituut (2018) NPR 9998:2018 nl. Beoordeling van de construc-tieve veiligheid van een gebouw bij nieuwbouw, verbouw en afkeuren - Geïnduceerde aardbevingen - Grondslagen, belastingen en weerstanden. Delft, The Netherlands (in Dutch)

Ötes A, Löring S (2003) Tastversuche zur Identifizierung des Verhaltensfaktors von Mauerwerksbauten für den Erdbebennachweis. Abschlussbericht. Lehrstuhl für Tragkonstruktionen, Universität Dortmund (in German) (Primary reference not available; data are provided in Morandi et al. 2018)

Penna A, Morandi P, Rota M, Manzini CF, Da Porto F, Magenes G (2014) Performance of masonry buildings during the Emilia 2012 earthquake. Bull Earthq Eng 12(5):2255-2273. https://doi.org/10.1007/ s10518-013-9496-6

Potter SH, Becker JS, Johnston DM, Rossiter KP (2015) An overview of the impacts of the 2010-2011 Canterbury earthquakes. Int J Disaster Risk Reduct 14:6-14. https://doi.org/10.1016/j.ijdrr.2015.01.014

Salmanpour AH, Mojsilović N, Schwartz J (2015) Displacement capacity of contemporary unreinforced masonry walls: an experimental study. Eng Struct 89:1-16. https://doi.org/10.1016/j.engst ruct.2015.01.052

Skroumpelou G, Messali F, Esposito R, Rots JG (2018) Mechanical characterisation of wall tie connection in cavity walls. In: Proceeding of the 10th Australasian masonry conference, Sydney, Australia

Tomassetti U, Correia AA, Candeias PX, Graziotti F, Costa AC (2019) Two-way bending out-of-plane collapse of a full-scale URM building tested on a shake table. Bull Earthq Eng 17:2165-2198. https://doi. org/10.1007/s10518-018-0507-5

Tomaževič M (1999) Earthquake-resistant design of masonry buildings. Imperial College Press, London

Turnšek V, Čačovič F (1971) Some experimental results on the strength of brick masonry walls. In: Proceedings of the 2nd international brick masonry conference

van der Meer LJ, Martens DRW, Vermeltfoort AT (2013) UPT rectangular and flanged shear walls of highstrength CASIEL-TLM masonry: Experimental and numerical push-over analysis. Eng Struct 49:628642. https://doi.org/10.1016/j.engstruct.2012.11.021

Vlek C (2018) Induced earthquakes from long-term gas extraction in Groningen, The Netherlands: statistical analysis and prognosis for acceptable-risk regulation. Risk Anal 38(7):1455-1473. https://doi. org/10.1111/risa.12967

Wilding BV, Dolatshahi KM, Beyer K (2017) Influence of load history on the force-displacement response of in-plane loaded unreinforced masonry walls. Eng Struct 152:671-682. https://doi.org/10.1016/j. engstruct.2017.09.038

Zilch K, Finck W, Grabowski S, Schermer D, Scheufler W (2008) Test results on the behaviour of masonry under static cyclic in plane lateral loads. Deliverable D7.1.b, ESECMaSE Project. Retrieved February 20, 2019, from https://www.esecmase.org

Publisher's Note Springer Nature remains neutral with regard to jurisdictional claims in published maps and institutional affiliations. 


\section{Affiliations}

\section{F. Messali ${ }^{1}$ (D) R. Esposito ${ }^{1}$ (D) . G. J. P. Ravenshorst ${ }^{2}$ - J. G. Rots ${ }^{1}$}

R. Esposito

r.esposito@tudelft.nl

G. J. P. Ravenshorst

g.j.p.ravenshorst@tudelft.nl

J. G. Rots

j.g.rots@tudelft.nl

1 Department of Materials, Mechanics, Management and Design, Delft University of Technology, Stevinweg 1, 2628CN Delft, The Netherlands

2 Department of Engineering Structures, Delft University of Technology, Stevinweg 1, 2628CN Delft, The Netherlands 